\title{
IDENTIDAD NACIONAL Y LEGITIMIDAD DEL TRIBUNAL DE JUSTICIA
}

\author{
MIGUEL AZPITARTE SÁNCHEZ \\ Profesor Titular de Derecho Constitucional \\ Universidad de Granada
}

SUMARIO

I. Identidad nacional y legitimidad del Tribunal de Justicia. II. Retales de teoría general. III. Los ámbitos de la identidad nacional. IV. A modo de conclusión.

\section{IDENTIDAD NACIONAL Y LEGITIMIDAD DEL TRIBUNAL DE JUSTICIA}

Es un tema clásico del derecho público la reflexión sobre la legitimidad de los órganos que cierran la organización judicial y entre cuyas funciones, además de garantizar un grado de coherencia en el sistema normativo, tienen la de enjuiciar la validez o determinar la aplicación de las fuentes, en especial las que requieren aprobación parlamentaria. El asunto nos remite en esencia a dos vértices: el método utilizado en la construcción de la decisión judicial; y cómo se ordena la relación de la jurisdicción con los restantes poderes constitucionales, para lo que se atiende al menos a los presupuestos procesales que la activan y a los efectos de sus resoluciones.

El Tribunal de Justicia, en el marco de este debate, se caracteriza por apartarse de la fórmula clásica del dilema contramayoritario ${ }^{1}$. Esto se debe sobre todo a que los procedimientos normativos de la Unión, incluso cuando utilizan sinónimos que remiten a la ley, están diseñados desde sus inicios para fomentar el consenso o un acuerdo de amplia base, alejado de la dicotomía mayoría/minoría,

1 Existen, sin embargo, algunos trabajos que siguen este tipo de análisis, EpPING, V., «Die demokratische Legitimation der dritten Gewalt der Europäischen Gemeinschaft», Der Staat, n. ${ }^{\circ}$ 36, 349-380, 1997; Loc Hong, Q., «Constitutional Review in the Mega-Leviathan: A Democratic Foundation for the European Court of Justice», European Law Review, vol. 16, n. ${ }^{\circ}$ 6, 695-716, 2010. 
que nutre la esencia política del Estado. Por ello es excepcional encontrar sentencias que resuelven la validez del Derecho derivado a partir de la impugnación de uno de los órganos que participó en el procedimiento normativo. La discusión sobre la validez o el Derecho aplicable surge del recurso de un Estado miembro, de la Comisión o de una cuestión prejudicial.

La posición del Tribunal de Justicia responde mucho mejor a los modelos en los que el órgano judicial supremo arbitra los conflictos centro/periferia. Este tipo de disputa en el Derecho de la Unión se ha sintetizado a través de una serie de variables. Primera, el proceso de integración, en virtud de la atribución de competencias derivadas de la Constitución, disminuye los ámbitos en los que el poder legislativo estatal se manifiesta ex novo. Segunda, en la transposición del Derecho derivado, se detecta una preponderancia del Ejecutivo sobre el Parlamento. Y, tercera, junto a los límites constitucionales, la Unión añade ahora toda una panoplia de barreras, lo cual supone una variación cuantitativa frente a las escogidos hitos de la norma suprema y también cualitativa, en tanto que el pedigrí de las nuevas constricciones al legislador no responde habitualmente a los contenidos esperados de un freno constitucional.

El lugar que asume el Tribunal de Justicia en este contexto ha sido sobradamente documentado. En síntesis, se puede decir que cobró especial relevancia mediante una jurisprudencia que amplió exponencialmente los derechos subjetivos de los ciudadanos. Así, el desplazamiento del Derecho estatal por el juez ordinario, en especial la ley, circunstancia inédita en muchos Estados, se admitió precisamente porque su fin último era la garantía de un derecho subjetivo².

Quizá no siempre se ha hecho notar que esta política jurisdiccional del Tribunal de Justicia coincidió en el tiempo con el surgimiento y asentamiento de una nueva comprensión del Derecho constitucional que marcaba el acento en la protección de los derechos fundamentales. Aunque los intereses subjetivos que amparaba el Tribunal de Justicia raramente coincidían con los que conocían las jurisdicciones supremas nacionales, en especial las constitucionales, su hilo conductor era el mismo: poner coto a la mayoría. Por ello no es casualidad que se haya justificado la intervención del Tribunal de Justicia adaptando la teoría de John Ely, que sirvió para explicar el activismo en la defensa de los derechos fundamentales del Tribunal Supremo de los Estados Unidos ${ }^{3}$. En efecto, allí la protección jurisdiccional de los derechos se construyó sobre la necesidad de incluir en la norma legislativa a aquellas minorías que no habían sido tenidas en cuenta en el procedimiento normativo, perfeccionando la representación. Del mismo

2 Creo que sigue siendo un trabajo de referencia en esta explicación la obra colectiva The European Court and National Courts-Doctrine and Jurisprudence, dir. Slaughter/Sweet/Weiler, Ed. Hart Publishing, Oxford, 1998.

3 Sobre la famosa nota al pie de Carolene Products, base conceptual de lo que serán los Tribunales Warren y Brown, véase a partir del capítulo 11, WoLFe, C., La transformación de la interpretación constitucional, Civitas, 1991. 
modo, en el ámbito del Derecho de la Unión, se ha sostenido que el principio de no discriminación por motivos de nacionalidad, en sus distintas formas normativas, sirve para incluir al extranjero en el procedimiento normativo de un Estado miembro, que de otra forma no lo tendría en cuenta ${ }^{4}$.

A los fines de este trabajo, interesa recordar las técnicas que el Tribunal de Justicia tradicionalmente ha utilizado para ordenar la disputa centro/periferia. El foco de atención lo han copado las libertades fundamentales, puesto que el generoso concepto de obstáculo a la libre circulación de factores productivos, le ha permitido al Tribunal evaluar amplios ámbitos de actuación de los Estados ${ }^{5}$. En las últimas décadas el valor normativo de la ciudadanía irrumpió con fuerza, abriendo un esquema de trabajo similar al de las libertades fundamentales, pero sin necesidad de sustanciar la dimensión económica ${ }^{6}$. Ha recibido una atención menor, pese a su gran importancia, todo lo relativo a la interpretación y aplicación de la normativa armonizada, seguramente porque está atravesado de especialidades (consumidores, medio ambiente, etc.) que hacen difícil encapsular el perfil metodológico ${ }^{7}$. Los derechos fundamentales de la Unión solo ahora empiezan a manifestar contornos referidos al contrapeso Unión/Estados miembros, ya que durante mucho tiempo su valor respondía a la necesidad de asegurar la primacía del Derecho europeo (cuestión que, obviamente, no es ajena al juego Unión/Estados) ${ }^{8}$. Y, sin duda, paradójicamente, el conflicto competencial puro ha tenido una escasísima relevancia, circunstancia que refleja la utilidad del procedimiento normativo de la Unión para ahormar esta tensión?.

4 Somek, A., «The Argument from Transnational Effects I: Representing Outsiders through Freedom of Movement», European Law Journal, vol. 16, n. ${ }^{\circ} 3$, 2010, pp. 315-344, en especial p. 30.

5 Es este un debate de bibliografía inabarcable. Pero se ejemplifica perfectamente en las Conclusiones del Abogado General M. Maduro Poiares a Alfa Vita, cuando titula sus reflexiones en el apartado 37 con la siguiente rúbrica «El artículo 30 del Tratado, ¿es una norma de liberalización de los intercambios intracomunitarios o una norma destinada, más en general, a promover el libre ejercicio de la actividad comercial en los distintos Estados miembros?», Conclusiones de 30 de marzo de 2006, Alfa Vita, C-158/04 y C 159/04, EU:C:2006:212

6 A los efectos de este trabajo me quiero limitar a un reciente trabajo, que expone con brillantez todos los perfiles de la categoría, LiÑ́́n Nogueras, D., "Ciudadanía Europea», en Tratado de Derecho y Políticas de la Unión Europea, Tomo VIII, dir. J.M. Beneyto Pérez, CEU y Thomson Reuters Aranzadi, 2016.

7 Un intento de destacar estos problemas lo encontramos en Arzoz SAntisteban, X., «Métodos de transposición y requisitos jurídicos europeos e internos», en AA.VV, Transposición de Directivas y autogobierno, dir. X. Arzoz Santisteban, Institut d'Estudis autonòmics, n. ${ }^{\circ}$ 85, 2013, en especial pp. 75-87. Y en el mismo libro mi ensayo «El contexto de la Directiva: principios jurídicos que ordenan el reparto de responsabilidades sobre la producción normativa de la Unión Europea», en especial pp. 23-54.

8 Respecto a la perspectiva de los derechos fundamentales en el equilibrio centro/periferia, véase mi trabajo «Los derechos fundamentales de la Unión en busca de un nuevo equilibrio», Revista Española de Derecho Constitucional, n. ${ }^{\circ} 104,243-268,2015$, en especial pp. 245-258. Sobre los nuevos movimientos del péndulo, Martín Rodríguez, P.J., «La emergencia de los límites constitucionales de la confianza mutua en el espacio de libertad, seguridad y justicia en la Sentencia del Tribunal de Justicia Aranyosi y Căldăraru», Revista de Derecho Comunitario Europeo, n. ${ }^{\circ}$ 55, 859-900, 2016.

9 No obstante, encontramos alguna excepción, por ejemplo, recientemente, Sentencia de 4 de mayo de 2016, República de Polonia c. Parlamento y Consejo, C-358/14, EU:C:2016:323. 
Ahora bien, la tesis de la que parte este trabajo mantiene que la crisis económica ha transformado el contexto en el que se desenvuelve el Tribunal de Justicia $\mathrm{y}$, por tanto, hemos de estar atentos al modo de sus decisiones, sea por las variaciones en el uso de las técnicas clásicas o el surgimiento de otras nuevas ${ }^{10}$. En mi opinión, el entorno ha cambiado al menos por una serie de razones notorias: el conflicto político ha irrumpido con toda su crudeza y los procesos normativos no han podido neutralizarlo; en su lugar se han instalado procedimientos para-comunitarios regidos por la lógica del derecho privado; esto, a su vez, ha provocado una minusvaloración del momento electoral en algunos Estados miembros.

La necesidad de aliviar los apuros de liquidez y solvencia de ciertos Estados miembros introdujo en el escenario europeo una imagen inédita, que exponía a la Unión tomando o forzando decisiones que empobrecían a grupos amplios de población. Desde entonces, el optimismo del proceso de integración ha llegado a su fin y ha sido sustituido por un profundo conflicto político-social, en el que aparecen marcadas divisiones ideológicas, muchas de las cuales incluso critican la esencia de la Unión y la naturaleza del constitucionalismo. La disputa ideológica propia del Estado miembro ha entrado en el corazón de la Unión, cuyos procedimientos de decisión, como ya se ha señalado, abjuran del enfrentamiento mayoría/minoría, a sabiendas de que en ese escenario la minoría suele coincidir con un Estado en bloque, lo que dificulta una salida eficiente.

La respuesta coyuntural a esta situación inédita fue en apariencia clásica, pues se recurrió, al igual que otras muchas veces, a soluciones intergubernamentales organizadas fuera del sistema de fuentes ordinario. Sin embargo, esta vez se antoja compleja su comunitarización a medio o largo plazo, porque el Mecanismo Europeo de Estabilidad (MEDE) introduce dos variables que rompen con la lógica política propia de la Unión (de derecho público), introduciendo principios que se insertan en verdad dentro del marco conceptual del derecho privado. De un lado, la toma de decisiones no atiende al peso poblacional de los Estados que componen la organización internacional, sino al derecho de propiedad, de suerte que el voto está regido por el número de acciones desembolsadas. De otro, la transferencia de fondos se aleja del concepto de solidaridad típico del derecho público, marcado por la redistribución; puesto que el MEDE concede préstamos sometidos a estricta condicionalidad, obligaciones de hacer cuyo cumplimiento es imprescindible para recibir el dinero.

El experimento del referéndum griego nos recuerda que la estricta condicionalidad es el síntoma más claro del desplazamiento que el momento electoral está padeciendo en los Estados miembros. Pero no es el único. En el último lustro observamos con naturalidad cómo el procedimiento del Semestre europeo incide

10 Por ejemplo, respecto a la ciudadanía ya se ha señalado una cierta retracción en la Sentencia del Tribunal de Justicia de 11 de noviembre de 2014, Dano, C-333/13, EU:C:2014:2358. Me remito a la interesante contextualización de Farahat, A., «Solidarität und Inklusion -Umstritenne Dimensionen der Unionsbürgerschaft—», Die Öffentliche Verwaltung, n. ${ }^{\circ}$ 2, 45-55, 2016. 
directamente sobre la política presupuestaria y económica de los Estados, dejando en agua de borrajas o al menos cambiando el sentido del debate presupuestario y los programas de gobierno. Hemos visto la formación de Ejecutivos técnicos auspiciados oficiosamente por instancias internacionales y recomendaciones en favor de gobiernos de gran coalición. Y, finalmente, algunos Estados han tramitado reformas constitucionales con un urgencia impropia de esta fuente, bajo el impulso del Banco Central Europeo.

El nuevo contexto político-constitucional anima a diseñar un proyecto investigador que indague en torno a las técnicas que utiliza el Tribunal de Justicia para ahormar el equilibrio entre la Unión y los Estados miembros. En mi opinión, junto a los instrumentos tradicionales, aparecen ahora dos grandes campos de interpretación que ofrecen novedades. El primero tiene que ver con el juicio que han merecido las decisiones de la Unión encaminadas a montar las estructuras de salvamento de los Estados miembros. Pringle ${ }^{11}$, Ganweiler ${ }^{12}$ y Ledra ${ }^{13}$ ofrecen un material rico para estudiar la manera en la que el Tribunal de Justicia ha justificado el refuerzo del intergubernamentalismo, la generación de entramados paracomunitarios y el nuevo papel del BCE, así como los débiles intentos de redistribución.

El segundo, objeto de este estudio, trata de la cláusula de identidad nacional dispuesta en el artículo 4 del Tratado de la Unión. Me parece que era una categoría llamada a cumplir una función más bien simbólica o político-constitucional ${ }^{14}$, pero de escaso peso como regla capaz de solventar controversias concretas, si no fuera porque el Tribunal Constitucional de la República Federal Alemana quiere hacer de otra similar, la identidad constitucional, una barrera absoluta frente al Derecho de la

11 Sentencia de 27 de noviembre de 2012, Pringle, C-370/12, EU:C:2012:756.

12 Sentencia de 16 de junio de 2015, Gauweiler, C-62/14, EU:C:2015:400.

13 Sentencia de 20 de septiembre de 2016, Ledra, C-8/15 P y C-10/15 P, EU:C:2016:701.

14 Categoría que nace en paralelo y para contrapesar las de Unión y Ciudadanía, y que funcionaría como sustitutivo de la terminología soberanista, Cruz Villalón, P., «La identidad constitucional de los Estados Miembros: dos relatos europeos», Anuario de la Facultad de Derecho de la Universidad Autónoma de Madrid, n. ${ }^{\circ}$ 17, 501-514, 2013, pp. 503 y 507. Para Rubio Llorente el salto de lo simbólico a lo jurídico se habría producido tras las reformas del Tratado de Lisboa y su vinculación «a las estructuras fundamentales políticas y constitucionales de éstos», Rubio Llorente, F., «Derechos fundamentales, principios estructurales y respeto por la identidad nacional de los Estados miembros de la Unión», Anuario de la Facultad de Derecho de la Universidad Autónoma de Madrid, n. ${ }^{\circ}$ 17, 515-527, 2013, p. 522. Agustín Menéndez entiende que el Tratado solo quiso recoger la idea de contralímites, MENÉndeZ MEnÉndez, A., «Una concepción alternativa de la identidad constitucional en el Derecho comunitario: de las excepciones idiosincráticas a la resistencia constitucional colectiva», Anuario de la Facultad de Derecho de la Universidad Autónoma de Madrid, n. ${ }^{\circ} 17,561$ 589, 2013, p. 565. La lectura alemana siempre ha visto en este precepto una garantía frente a la desaparición del Estado o la evolución de la Unión a la forma de un Estado federal, HARATsCH, A., «Nationale Identität aus europarechtlicher Sicht», Europarecht, n. $^{\circ}$ 2, 131-146, 2016, p. 133; ClaEs, M., y ReEstMAN, J-H., «The Protection of National Constitutional Identity and theLimits of European Integration at the Occasion of the Gauweiler Case», German Law Journal, vol. 16, n. ${ }^{\circ}$ 4, 917-970, 2015, p. 932. Y no hemos de olvidar que en la elaboración del Tratado Constitucional se concibió siempre como una cláusula que, al igual que el principio de subsidiariedad o proporcionalidad, tenía como fin contener el ejercicio competencial de la Unión, GUASTAFerro, B., «Beyond the Exceptionalism of Constitutional Conflicts: The Ordinary Functions of the Identity Clause», Yearbook of European Law, vol. 31, n. ${ }^{\circ} 1,263-318,2012$, pp. 275 y 282. 
Unión ${ }^{15}$. Nos encontramos así con la incógnita central de saber si el concepto normativo de identidad sirve para ordenar los conflictos Unión/Estados miembros ${ }^{16}$.

La metodología utilizada por ese trabajo es la propia del comentario jurisprudencial ${ }^{17}$. Son varias las razones que invita a escoger este camino. En primer lugar, me parece que a menudo nos movemos en una confusión entre la función ideal y la real que a día de hoy corresponde a la categoría de identidad nacional. Conviene, por tanto, hacer una foto lo más completa posible del estado de la cuestión. En segundo lugar, ese desajuste es en parte tributario del propio Tribunal de Justicia, que todavía no ha cerrado una doctrina jurisprudencial y sigue tanteando las posibilidades de este criterio normativo. Así las cosas, con la ordenación y análisis de la jurisprudencia — en especial las Conclusiones generales - quiero mostrar la imagen poliédrica de discursos en formación; la sociedad abierta de los intérpretes constitucionales aún busca un uso controlable de la categoría. De acuerdo con este método, en las páginas que siguen dedicaré el epígrafe II a intentar componer las premisas de teoría general que articulan el uso jurisprudencial de la identidad nacional. En el epígrafe III, sin dejar implícitamente de desempeñar la misma labor que en el II, pruebo a clasificar los ámbitos temáticos en los que juega la categoría. Finalmente, en el último punto esbozo unas conclusiones sintéticas.

\section{RETALES DE TEORÍA GENERAL}

\section{La identidad nacional de Derecho de la Unión no habilita la potestad de los órganos jurisdiccionales ordinarios para imponer la identidad constitucional estatal}

Merece la pena comenzar con las Conclusiones del Abogado General Pedro Cruz Villalón en Gauweiler ${ }^{18}$, que han deslindado con nitidez las categorías de

15 Cruz Villalón, P., ibidem, p. 507 para todos los Tribunales Constitucionales. Centrado en el Tribunal Constitucional de Alemania, véase mi trabajo, «Integración y legitimidad de la jurisdicción constitucional», Revista de Derecho Comunitario Europeo, n. ${ }^{\circ}$ 55, 941-975, 2016; en este ensayo pueden encontrarse referencias al debate doctrinal alemán en torno a la categoría de identidad constitucional.

16 Para empezar, como señala Rubio Llorente, la identidad nacional trastoca el sentido de las cuestiones prejudiciales. El juez —el Tribunal Constitucional— ya no pregunta para saber si una norma estatal es aplicable, sino que interroga sobre la aplicabilidad del Derecho de la Unión, Rubio Llorente, op. cit., n. ${ }^{\circ} 14$, p. 525. Se debe estar atento, por lo demás, a la tesis de Agustín Menéndez quien considera que el principio ya formaba parte del «derecho constitucional profundo» del proceso de integración (en el mismo sentido más adelante las Conclusiones de Maduro a Machiniki) y que las controversias jurisdiccionales se resolverían igual sin esta categoría; por ello propone leerlo en su dimensión política, como instrumento útil para la «resistencia constitucional» Menéndez Menéndez, A., op. cit., n. ${ }^{\circ}$ 14, pp. 568 y ss.; pp. 578 y ss.

$17 \mathrm{Ni}$ que decir tiene que la mayoría de las Sentencias y Conclusiones que se comentan en la parte II y III han recibido atención monográfica en amplia bibliografía. Por puras razones de economía formal voy a prescindir de traerlas al ensayo, centrándome exclusivamente en la bibliografía referida a la identidad nacional.

18 Conclusiones de 14 de enero de 2015, Gauweiler, C-62/14, EU:C:2015:7. 
identidad nacional y/o constitucional ${ }^{19}$. El asunto es bien conocido: el Tribunal Constitucional Federal Alemán planteó una cuestión prejudicial en la que discutía la conformidad con el Derecho de la Unión de la decisión del Banco Central Europeo de comprar deuda pública en los mercados secundarios. Pero no fue un incidente procesal más, puesto que, además de subrayar las dudas a la luz del Derecho de la Unión, la jurisdicción constitucional advirtió sobre el ejercicio de un control ulterior desde la Constitución alemana, en especial a partir de la identidad constitucional, concebida como un núcleo irreductible, distinto de la identidad nacional recogida en el artículo 4 del TUE.

El Abogado General califica como «dificultad funcional» la hipótesis que hasta ese momento solo se había esbozado en términos teóricos, a saber, la posibilidad de que la judicatura nacional se apartase frontalmente de una sentencia del Tribunal de Justicia. ¿Es la identidad nacional, en tal escenario de choque de legitimidades, una categoría normativa útil? Las Conclusiones componen la respuesta en dos pasos. El primero niega espacio a una determinada comprensión de la identidad nacional; el segundo ofrece conceptos alternativos para resolver el conflicto.

Pedro Cruz Villalón corta el camino a una categoría irreductible, de contenido inespecífico y a concretar por los órganos jurisdiccionales nacionales (apdo. 59 y 60). De ahí que afirme «(...) tal reserva de identidad (...) dejaría muy probablemente al ordenamiento de la Unión en una posición residual, al menos en términos cuantitativos». Está por saber qué sentido encierra para el Abogado General el término «cualitativamente residual», pero a nadie se le escapa que la tesis de una identidad nacional que frenase la primacía del Derecho de la Unión y en especial el carácter vinculante de las sentencias del Tribunal de Justica, situaría a este ordenamiento en un lugar subordinado. Así las cosas, sería incomprensible que el Tribunal de Justicia aceptase un concepto de esta naturaleza para mediar en la disputa centro/periferia. No puede serle útil. Por ello, el Abogado General se ve obligado a poner en juego alternativas.

Primero, las «tradiciones constitucionales comunes», que conforman una «cultura constitucional» que sería parte de una «identidad común de la Unión», con la importante consecuencia, dice el Abogado General, «de que la identidad constitucional de cada Estado miembro, específica desde luego en la medida en que a ello haya lugar, no puede sentirse a una distancia astronómica de dicha cultura constitucional común» (apdo. 61). Más aún, en el «medio y largo plazo» debería existir un «principio de confluencia básica entre la identidad constitucional de la Unión y la de cada uno de los Estados miembros» (apdo. 61).

El giro metodológico es evidente. Junto al rechazo de una categoría a interpretar por los órganos jurisdiccionales estatales, se propone un concepto propio del Derecho de la Unión y a definir en última instancia por el Tribunal de

19 En la Sentencia, sin embargo, la cuestión de la identidad nacional carece de importancia. 
Justicia. Pero no es solo una diferencia respecto al garante último de la exacta interpretación, sino que las «tradiciones constitucionales comunes» se escogen a sabiendas de su naturaleza magmática, permeable, que va de lo plural a lo común.

Esta confluencia básica entre identidades constitucionales se completa con el concepto de cooperación leal, de la que el Abogado General extrae principios operativos específicos. Antes de nada una expectativa:

«El deseable resultado final sería el de que un eventual control sucesivo construido sobre la base de los parámetros constitucionales, en las circunstancias del caso, no alcanzara conclusiones en abierta contradicción con la respuesta del Tribunal de Justicia» (apdo. 63).

Es interesante detenerse en esta afirmación, porque no niega, sino que más bien presume, el uso de la identidad constitucional en las jurisdicciones estatales, pero espera que las tradiciones constitucionales comunes y la cooperación leal generen un punto de encuentro o al menos eviten una contradicción frontal (apdo. 63). Premisa que implica condiciones procesales ulteriores. Del lado del Tribunal de Justicia, que dé una respuesta constructiva sobre el fondo del asunto (apdo. 66 - había una seria objeción sobre la admisión de la cuestión prejudicial). Y por parte del Tribunal Constitucional estatal, que asuma como suficiente y definitiva la respuesta para atender a las pretensiones de la controversia concreta (apdo. 67) ${ }^{20}$.

El uso de la cooperación leal para trazar técnicas que salven la operatividad del control de comunitariedad y el juicio de constitucionalidad retoma la reflexión paralela hilvanada años antes por el Abogado Miguel Poiares Maduro en el asunto Michaniki $i^{21}$. Se juzgó entonces la pertinencia de una prohibición prevista en la Constitución griega que impedía al propietario, socio, accionista principal o directivo de una empresa de medios de comunicación ser adjudicatario de un contrato público. Para abordar la cuestión, Maduro reconoció sin ambages el deber de la Unión de respetar la identidad nacional («constitucional», en sentido estricto):

«Es cierto que el respeto de la identidad constitucional de los Estados miembros constituye un deber para la Unión Europea. Este deber le fue impuesto desde su origen. En efecto, forma parte de la propia esencia del proyecto europeo iniciado a principios de los años cincuenta, que consiste en avanzar sobre la vía de la integración preservando al mismo tiempo la existencia política de los Estados (apdo. 31)»

Pero sin solución de continuidad niega el carácter absoluto del deber, pues de lo contrario surgiría el riesgo de discriminación de los Estados Miembros o

20 Así ha sido finalmente, si bien de una forma un tanto particular. El TCFA considera que el Tribunal de Justicia no ha resuelto adecuadamente la cuestión prejudicial, pero tolera la respuesta en tanto que acepta un margen de error, AzPitarte SÁnchez, M., op. cit., n. ${ }^{\circ}$ 15, p. 957.

21 Conclusiones de 8 de octubre de 2008, Michaniki, C-213/07, EU:C:2008:544. 
que estos utilizaran sus normas constitucionales para esquivar el cumplimiento del Derecho de la Unión. Y esto le lleva a afirmar: "Al igual que el Derecho comunitario tiene en cuenta la identidad constitucional de los Estados miembros, el Derecho constitucional nacional debe adaptarse a las exigencias del ordenamiento jurídico comunitario» (apdo. 33).

Esta declaración y la propuesta de Pedro Cruz Villalón en Gawweiler postulan la idea de que la primacía del Derecho de la Unión no es materialmente absoluta, en tanto que admite ser moldeada por las singularidades del Derecho constitucional estatal. Pero este, a su vez, no se impone en su conjunto ni ante cualquier circunstancia. Existe una relación de contención recíproca entre el deber de respeto a la identidad nacional y la supremacía constitucional; su contexto parece ser la proscripción de discriminación entre Estados. Cómo trazar esa relación, el método, su estilo, es la clave.

\section{La identidad nacional ha de componerse de normas constitucionales. Pero no la integra cualquier norma de la Constitución estatal}

La identidad nacional no coincide con la identidad constitucional si esta última ha de ser concretada y aplicada unilateralmente por un juez del Estado miembro. Desechada esta hipótesis, el interrogante radica en saber en qué circunstancias sirve como vía de mediación para introducir en el Derecho de la Unión referencias normativas estatales. Este es el tema dirimido en Torresi ${ }^{22}$, que juzga la denegación por un Colegio de Abogados trasalpino de la inscripción a dos italianos, habilitados en España. El órgano que eleva la cuestión esgrime la identidad nacional para limitar la libre circulación, puesto que la Constitución italiana, estipula en el artículo 33.5 que «es preciso superar un examen estatal para obtener la habilitación del ejercicio de la profesión».

El Abogado General Nils Wahl resuelve el problema de manera expedita, pero aun así ofrece algunos asertos importantes. Advierte que la definición de la identidad nacional necesita un presupuesto estatal cualificado materialmente:

«No me parece evidente por qué la admisión en un Colegio de abogados de ciudadanos de la Unión que hayan obtenido un título profesional en otro Estado miembro amenazaría el ordenamiento jurídico italiano de tal forma que deba considerarse una vulneración de la identidad nacional italiana» (apd. 99).

Se requiere un grado de evidencia, por ello no «cualquier regla incluida en la Constitución nacional» (apdo. 100) es susceptible de integrar nuestra categoría objeto de estudio. Pero, en todo caso, fruto de una lectura a contrario, sí parece

22 Conclusiones de 10 de abril de 2014, Torresi, C-58/13 y C-59/13, EU:C:2014:265 
indispensable que la referencia normativa con vocación de sustanciar la identidad nacional ha de ser parte de la Norma suprema estatal o tener una conexión directa con ella.

Sin solución de continuidad y de nuevo en sintética expresión, Nils Wahl esboza la funcionalidad normativa de la identidad nacional (apdo. 100). Sirve para «limitar la aplicación uniforme de la disposiciones de la Unión» (concretamente de las libertades fundamentales) y «constituir parámetro de legalidad» del Derecho derivado. En definitiva, oficiaría una doble labor. La de una exigencia imperativa más que justifica una práctica nacional limitativa de una libertad fundamental; y la de cualquier norma de Derecho originario que condiciona las fuentes derivadas.

Las Conclusiones de Torresi se refieren expresamente a las del Abogado General Miguel Poiares Maduro en Michaniki, sin embargo, transforma el análisis de las últimas. Como ya se ha expuesto, versaban igualmente sobre una prohibición constitucional, concretamente la que impedía al propietario, socio, accionista principal o directivo de una empresa de medios de comunicación ser adjudicatario de un contrato público. Pero mientras que Nils Wahl exige una determinada cualidad material a la norma constitucional para que integre la identidad nacional, en cambio Maduro opera con la idea del margen de apreciación que el Derecho derivado deja al ordenamiento estatal.

En efecto, Maduro considera que la identidad nacional comprende la identidad constitucional del Estado Miembro (apdo. 31), lo cual no supone, sin embargo, la integración de cualquier norma de la Constitución estatal en la identidad nacional:

«No obstante, ha de precisarse que esa obligación de respetar la identidad constitucional de los Estados miembros no puede entenderse como una deferencia absoluta respecto a todas las normas constitucionales nacionales. Si así fuera, los Estados miembros podrían escudarse en las constituciones nacionales para eludir el Derecho comunitario en ámbitos determinados. Más aún, podrían surgir discriminaciones entre Estados miembros en función del contenido que cada uno de ellos diera a su Constitución.» (apdo. 33)

Entonces, la clave para tener en cuenta la normas constitucionales depende de la medida «en que estén comprendidas dentro del margen de apreciación del que disponen los Estados miembros para garantizar el respeto del principio de igualdad de trato impuesto por la directiva» (apdo. 33). Es decir, no es tanto la significación material de la regla constitucional, sino la potestad que el Derecho de la Unión da al Estado miembro para transponer, dentro de la cual cabe la modulación que exige una norma constitucional. Pero esta interpretación formal invita a pensar que en el margen de apreciación estatal para dar cumplimiento a los imperativos de la Unión es irrelevante si el condicionante nace de una norma constitucional o de otra de menor rango. Dicho de forma sencilla: gozando el 
Estado de un espacio de transposición, los criterios que utilizan para aprovecharlo quedan a su discreción, siempre con el debido respeto a los límites marcados por el Derecho de la Unión, en especial el principio de proporcionalidad (apdo. 35 ).

\section{Identidad nacional y derechos fundamentales estatales}

La referencia de Maduro a 0 mega ${ }^{23}$ abre otra importante senda de reflexión en torno a nuestra categoría de estudio. Concretamente, en Machiniki, el Abogado General afirmó:

«(...) el Tribunal de Justicia, tras confirmar que el ordenamiento jurídico comunitario protege la dignidad humana como principio general del Derecho, reconoció al Estado miembro una gran libertad para determinar su contenido y alcance según su concepción sobre la protección que requiere ese derecho fundamental en su territorio, habida cuenta de sus particularidades nacionales. En consecuencia, el hecho de que la concepción de un Estado miembro sobre un derecho fundamental no sea compartida por los demás Estados miembros no impide que dicho Estado miembro la invoque para justificar una restricción a la libre prestación de servicios. (apdo. 32)»

Y aunque en Omega el Tribunal de Justicia no utilizó la categoría de identidad nacional, sino la de orden público, ambas dibujan un problema idéntico y se entrecruzan continuamente. El caso de autos es de sobra conocido: una decisión municipal prohíbe en virtud de la dignidad humana que una empresa de entretenimiento ofrezca un juego que implica «simulaciones de homicidios», divertimento importado de otro Estado miembro. El conflicto jurídico queda así tasado entre la libertad fundamental a la libre prestación de servicios y la dignidad humana protegida en forma de derecho fundamental por una Constitución estatal, la alemana.

En este contexto, la Abogada General Christine Stix-Hackl ${ }^{24}$ aborda el asunto a partir de una distinción clave, relativa a la doble operatividad de los derechos fundamentales en su relación con las libertades fundamentales (y yo añado que es así con cualquier norma de Derecho de la Unión que pueda ser excepcionada por el Estado). Cuando el derecho fundamental está recogido por el ordenamiento europeo, se pondera con la libertad fundamental (apdo. 45 y 52). En cambio, si el Estado reconoce un derecho fundamental que no está garantizado en el ordenamiento de la Unión o lo protege con un contenido distinto, entra en juego como una medida estatal que de forma proporcionada puede limitar la libertad fundamental (apdo. 71 y ss.; siguiendo a la Abogada General, la Sentencia en apdo. 36-39).

24 Conclusiones de 18 de marzo de 2014, Omega, C-36/02, EU:C:2004:162. 
Conviene subrayar que en Omega el derecho fundamental estatal se insertó a través de la categoría de orden público, prevista para justificar las medidas estatales que excepcionan la aplicación de una libertad fundamental (hoy en el 36 TFUE). Categoría que ha de interpretarse de modo restrictivo y se activa solo si existe «una amenaza real y suficientemente grave que afecte a un interés fundamental de la sociedad» (apdo. 99). Pero, aún en el marco de estas exigentes condiciones, la Abogada General declaró que:

«En la aplicación de esta valoración, las autoridades nacionales disfrutan de un cierto margen de discrecionalidad. Así lo expresa también el Tribunal de Justicia al señalar que "el Derecho comunitario no impone a los Estados miembros una escala uniforme de valores en lo relativo a la apreciación de aquellos comportamientos que puedan considerarse contrarios al orden público"» (apdo. 101).

No hay duda de que Omega quebró la consistencia con la que tradicionalmente se apelaba a Internationale Handelsgesellschaft para negar cualquier relevancia del Derecho constitucional estatal ${ }^{25}$. La diversidad nacional, su diferencia respecto al canon común que se vuelca en los derechos fundamentales de la Unión, habría de tener cabida, al menos en lo referente a las libertades fundamentales, siempre como manifestación de la discrecionalidad de los Estados miembros para determinar el orden público. Es obvio, y no deja de ser importante, la similitud de este acercamiento con la metodología del TEDH y su técnica del margen de apreciación.

En este punto merece la pena traer a colación la posición del Abogado General en Melloni ${ }^{26}$. Aunque los contextos son distintos —en Omega la excepción a la aplicación de una libertad fundamental, en Melloni a la aplicación de una Directiva marco- la cuestión es sustancialmente la misma: ¿en qué medida puede el Derecho constitucional estatal frenar el Derecho de la Unión? ¿Qué categorías sirven para introducir la diversidad constitucional?

Las Conclusiones de Yves Bot son relevantes en cuanto que muestran tres formas de identificar los componentes de la identidad nacional. Hay, primero, un elemento procesal, a partir del cual la parte que alega la identidad nacional ha de explicar con coherencia por qué una norma estatal forma parte de la identidad nacional. Solo así se entiende que en el apartado 141 afirme:

«En efecto, además de que la determinación de lo que constituye el «contenido absoluto» del derecho de defensa sigue siendo debatida dentro del mismo Tribunal Constitucional, el propio Reino de España indicó en la vista, fundándose en especial en las excepciones existentes en el Derecho español a la celebración de un nuevo

25 En un recurso argumentativo habitual, la Abogada General no deja de referirse a esa decisión cuyo contundencia se modula, apdo. 69.

26 Conclusiones de 2 de octubre de 2012, Melloni, C-399/11, EU:C:2012:600. 
juicio tras una sentencia dictada en rebeldía, que la presencia del acusado en su juicio no forma parte de la identidad constitucional del Reino de España.»

En segundo lugar, declara que «no debe confundirse lo que corresponde a una concepción exigente de la protección de un derecho fundamental con una vulneración de la identidad nacional» (apdo. 142). Este es, quizás, el aspecto más relevante puesto que en cierta medida cuestiona el corolario de Omega, diluyendo la importancia de la diversidad nacional de un derecho fundamental en la modulación de la aplicación del ordenamiento de la Unión. Ciertamente, el punto de llegada en las Conclusiones a Melloni no podía ser otro después de la lectura que Yves Bot realiza del artículo 53 de la Carta, vedando una interpretación que salvase una mayor protección del Estado. Así, desde el momento en que el 53 del Carta es distinto al 53 del CEDH, pierde peso el camino abierto por Omega que invitaba a utilizar la categoría del orden público y el margen de apreciación como instrumentos para mediar en el equilibrio de los derechos fundamentales.

Y es que, en definitiva, los modelos de protección de los derechos fundamentales en la Unión y en el Convenio son distintos. Mientras que en el segundo no hay lugar al desarrollo normativo de los derechos fundamentales, para los de la Carta, en ocasiones las competencias de la Unión habilitan la regulación del ejercicio de un derecho. Desde esta advertencia se entiende una tercera apreciación de Yves Bot, recogida en el apartado 145:

«La adopción por el legislador de la Unión del artículo 4 bis de la Decisión marco demuestra que los Estados miembros quisieron establecer un criterio común sobre la ejecución de las órdenes de detención europeas emitidas para ejecutar sentencias dictadas en rebeldía y que ese criterio común era compatible con la diversidad de las tradiciones y de los sistemas jurídicos de los Estados miembros.»

Habría de sostenerse, según el Abogado General, que la opción de armonizar una materia relativa a los derechos fundamentales neutraliza la posibilidad de alegar a posteriori la identidad nacional. Al mismo tiempo esta idea subraya la importancia de hacer visible la identidad nacional en los procedimientos normativos. Es ahí donde los Gobiernos tienen la oportunidad de dar forma y articular la singularidad constitucional, de suerte que quede protegida en la conformación final de la norma. La identidad nacional se presenta como una categoría discursiva que se decanta en el debate político; en esta tesitura es más un principio político que ha de guiar la toma de decisiones que un hito sustancial y trascendente de peso jurisdiccional.

Esta posición relativiza el lugar que ocuparía la jurisdicción estatal en la definición de la identidad nacional. Al actualizarse en el procedimiento normativo, se rebajan las expectativas y posibilidades de que un Tribunal imponga de forma absoluta una determinada comprensión. Es más, pone en tela de juicio que en sí mismo sea un concepto útil en términos jurisdiccionales. Repito, el 
Abogado General Yves Bot nos lanza la disyuntiva de valorar si estamos ante una categoría político-constitucional que ha de guiar el debate siempre abierto y flexible de la creación de normas, o realmente nos encontramos ante una figura cuya esencia ha de ser destilada por un juez.

\section{LOS ÁMBITOS DE LA IDENTIDAD NACIONAL}

\section{La autonomía territorial}

El vínculo entre identidad nacional y autonomía territorial de los Estados miembros se hace presente en las Conclusiones de la Abogada General Juliane Kokott al asunto UGT-Rioja ${ }^{27}$. Recordemos que se juzgaba la potestad tributaria de las Diputaciones vascas para establecer un tipo del impuesto de sociedades más bajo que el general regulado por la ley estatal. Y si bien es cierto que la Abogada General se concentró en realizar una aplicación de la doctrina Azores, introducida dos años antes por el Tribunal de Justicia ${ }^{28}$, la diferencia más relevante a efectos de este ensayo es el uso inédito de la identidad nacional ${ }^{29}$.

Recuerda la Abogada General el principio clásico de Derecho de la Unión que impide a un Estado miembro «invocar disposiciones, prácticas ni situaciones de su ordenamiento jurídico interno, incluidas las resultantes de la estructura constitucional de dicho Estado, para justificar el incumplimiento de las obligaciones derivadas del Derecho comunitario» (apdo. 55). En contrapartida, la identidad nacional «implica que la Unión no afecta al ordenamiento constitucional de un Estado miembro, sea centralizado o federal, y, en principio, tampoco influye en el reparto de competencias dentro de un Estado miembro» (apdo. 54). En definitiva, la estructura territorial nacional configurada en la Constitución resistiría o al menos modularía las aplicaciones del Derecho de la Unión que vacíen su sentido.

Por ejemplo, la Abogada General, en lo tocante a la diversidad tributaria, encuentra un punto medio entre ambos principios, puesto que si cualquier medida impositiva infra estatal se considerase en sí misma selectiva «la autonomía que concede a la entidad territorial la Constitución nacional quedaría gravemente en entredicho» (apdo. 56). Por ello, en este caso la argumentación se centró en analizar si las medidas tributarias establecidas por los Territorios

27 Conclusiones de 8 de mayo de 2008, UGT-Rioja, C-428/06 y otros, EU:C:2008:262.

28 Sentencia de 6 de septiembre de 2006, República Portuguesa y otros c. Comisión, C-88/03, EU:C:2006:511.

29 En la Sentencia de 11 de septiembre de 2008, UGT-Rioja, C-428/06 y otros, EU:C:2008:488, el concepto ni siquiera aparece. 
forales respondían a una verdadera autonomía institucional, procedimental y económica $^{30}$, presupuestos que frenarían la primacía del Derecho de la Unión.

A partir de este asunto, la identidad nacional se ha ido consolidando como una categoría útil para proteger el ejercicio efectivo de las competencias constitucionalmente garantizadas en favor de un ente territorial. La Sentencia del asunto Digibet lo ilustra con claridad. En él se evaluaba la restricción de la libre prestación de servicios en un régimen jurídico, el alemán, donde todos los Länder menos uno habían prohibido los juegos de azar por internet; esa falta de coherencia - la excepción de un territorio que sí permitía el juego- haría patente el obstáculo en aquellos que lo prohibían.

La Sentencia es interesante porque construye en parte la justificación de la restricción a libre prestación de servicios evocando la categoría del margen de apreciación del Estado, que como ya se ha señalado entronca con el modo de proceder del TEDH. En el apartado 24 afirma:

«(...) la normativa en materia de juegos de azar se cuenta entre los ámbitos en que se dan considerables divergencias morales, religiosas y culturales entre los Estados miembros. A falta de armonización de la Unión en la materia, corresponde a cada Estado miembro apreciar en estos ámbitos, conforme a su propia escala de valores, las exigencias que supone la protección de los intereses afectados.»

La divergencia de valores sería entonces la razón que habilita la intervención restrictiva estatal. Ahora bien, en busca del estilo y el método utilizado por el Tribunal de Justicia, es igualmente importante indagar sobre el fundamento utilizado para introducir esa disparidad «moral, religiosa o cultural» que excepciona el Derecho originario, más concretamente las libertades fundamentales. Y es que en esta Sentencia aparecen de modo sumario tres criterios que se yuxtaponen, pese a que su régimen jurídico no es idéntico. El orden público (apdo. 22), que ya sabemos que recibe una interpretación rigurosa y da cabida a cualquier medida estatal que tenga que ver con las singularidades reseñadas, sin necesidad de un expreso reconocimiento constitucional. Las razones imperiosas de interés general o exigencias imperativas (entre las que el orden público es una especialidad), cláusula general para justificar las restricción estatal a las libertades fundamentales que admite a priori cualquier motivo de interés general, sin que deba tener conexión específica con las particularidades morales o culturales de un Estado miembro. Y, en tercer lugar, la identidad constitucional que es útil para salvar la distribución competencial del Estado miembro, dado que «no puede cuestionarse el reparto de competencias entre los Länder, puesto que éste resulta amparado por la protección que confiere el artículo 4 TUE, apartado 2, en virtud del cual la Unión respetará la identidad nacional de los Estados» (apdo. 34).

30 Sobre el sentido de esta triple naturaleza de la autonomía, apdo. 52. 
El uso complementario de estas tres razones obliga a una serie de matizaciones. Una lectura atenta denota que la cláusula de orden público y las razones imperiosas conforman, por decirlo de algún modo, un límite material a la eficacia de las libertades fundamentales (en verdad, el orden público es una exigencia imperativa más). El Tribunal de Justicia y con él los tribunales nacionales han de embarcarse en un análisis sustancial de dos pasos. El primero consistiría en determinar si la medida estatal goza de calidad suficiente para integrarse en la categoría normativa; se trata de un juicio de valor. El segundo, a través del principio de proporcionalidad, moderaría esa pura elección entre valores — la libertad fundamental y el encarnado por la medida estatal- dándole razonabilidad, en definitiva, universalidad. Principio de proporcionalidad que se ensancha cuando además viene acompañado de un margen de apreciación, que obviamente no es sino una deferencia a favor del Estado en la determinación de esos valores en conflicto de jerarquía.

Sin embargo, y aquí nace una significativa paradoja, la identidad constitucional, en principio llamada a dar pábulo a un juego de trascendencias, gira en el sentido contrario, generando un criterio de resolución formal allí donde el choque de valores invita a una dialéctica de alta densidad sustancial. Tanto en UGTRioja como en Digibet la identidad nacional sirve para proteger per se, parece que de manera absoluta, la diversidad que nace de la distribución competencial garantizada por la Constitución estatal. De este modo, cuando un ente regional ha ejercido su competencia de forma distinta al resto de unidades territoriales del Estado en el que se integra, no estamos ante una medida proteccionista, sino frente a la identidad nacional de ese Estado, materializada en el derecho a la diferencia regulatoria que asegura la Constitución.

Me atrevería a decir que la identidad nacional genera una presunción que devalúa el concepto de obstáculo a la libre circulación. Así las cosas, medidas que de ser adoptadas por un Estado miembro, privilegiando a sus nacionales frente a los otros ciudadanos de la Unión (o, dentro de sus propias fronteras, a unos territorios frente a otros), serían una barrera de difícil justificación, si las dicta un ente subestatal, son, en cambio, manifestación de la identidad constitucional.

Creo que un buen ejemplo de esta formalización de la identidad nacional lo encontramos en el asunto RegioPost ${ }^{31}$, en el que se juzga la competencia de un Land para exigir a los licitadores de contratos públicos el compromiso del pago de un salario mínimo a sus trabajadores. La disputa versaba en parte sobre la novedad incorporada por la Directiva 2004/18 que autoriza a los Estados miembros a establecer condiciones especiales de naturaleza laboral. Para la mercantil que suscitó el conflicto en sede nacional, así como para la Comisión, la exigencia de un salario mínimo afectaba a la libertad de prestación de servicios en tanto que las empresas procedentes de otros Estados miembros habían de correr con un

31 Conclusiones de 9 de septiembre de 2015, RegioPost, C-115-14, EU:C:2015:566. 
coste adicional. Además, defendían que tal salario mínimo solo tendría sentido si se extendía también a los contratos privados.

El Abogado General Paolo Mengozzi sale al paso de estas argumentaciones, agarrándose, sin más, a la identidad nacional y al principio de efectivo ejercicio de las competencias protegidas constitucionalmente:

«(...) En mi opinión, del artículo 4 TUE, apartado 2, se deriva que el Derecho de la Unión no puede privar a una entidad regional o local del ejercicio efectivo que las competencias que le han sido conferidas en el seno del Estado miembro de que se trate. Pues bien, como pretenden demostrar las consideraciones anteriores, ésta sería, en definitiva, la consecuencia del argumento formulado por RegioPost y la Comisión según el cual, para ser compatible con el artículo 56 TFUE, la norma contenida en el artículo 3 de la LTTG en beneficio de los trabajadores que ejecutan un contrato público debe ampliarse a los trabajadores adscritos a la ejecución de contratos privados.» (apdo. 84).

A la luz de estas Conclusiones la identidad nacional se presenta como un bastión firme de la estructura territorial de los Estados miembros, al menos de su organización competencial, de suerte que la diversidad dentro del Estado no quiebra el mercado interior. Hay, sin embargo, dos matices que modulan esta fortaleza: la identidad nacional es un concepto de Derecho de la Unión que fija en última instancia el Tribunal de Justicia; la identidad nacional cede ante los derechos fundamentales.

Respecto a lo primero, son un buen ejemplo las Conclusiones de la Abogada General al asunto Comisión c. España, en que se evalúa el cumplimiento de una Directiva a través de una Orden ministerial a la que el Estado español quiere darle eficacia supletoria para satisfacer también la transposición por las Comunidades Autónomas que no han ejercido su competencia. En el alegato del Reino de España se defiende que la transposición supletoria del Derecho de la Unión sería parte de la identidad constitucional. Pero, en una lectura precisa de la jurisprudencia del Tribunal Constitucional, Kokott, le da la vuelta al argumento y afirma en el apartado 35:

«Al contrario: considerar que la aplicación supletoria de la normativa estatal constituye una vía aceptable de transposición de una directiva supondría una falta de respeto frente a la contención de que hace gala el Derecho constitucional español con respecto a la aplicación supletoria de la normativa estatal. Ello equivaldría a tener en poco la responsabilidad en materia legislativa que implican las competencias de las Comunidades Autónomas».

Curiosamente, el estatus constitucional de las Comunidades Autónomas es utilizado para frenar un uso espurio de la identidad nacional. Dicho de manera sencilla, es el Tribunal de Justicia y no el Estado miembro quien determina qué contenidos integran la identidad nacional. Encontramos así un corolario 
importante que contrapesa la fortaleza de esta cláusula como barrera de la aplicación del Derecho de la Unión. En efecto, la identidad nacional garantiza la estructura territorial del Estado, pero siempre sometida a un control de calidad por parte del Tribunal de Justicia en el que ha de verificar si el elemento que quiere introducirse en la categoría responde con certeza a ese postulado. Sin embargo, este mismo asunto nos muestra que el Tribunal de Justicia, o al menos su Abogada General, todavía no ha depurado la técnica interpretativa con la que distinguir qué piezas del régimen constitucional territorial pasan a ser parte de la identidad nacional ${ }^{32}$. Con todo, a la luz de estas Conclusiones parecería que el detenido análisis de la realidad constitucional estatal se convierte en el patrón que ha de marcar la sustancia de la identidad nacional.

Hay, por tanto, una delimitación interna del concepto de identidad nacional. Pero también externa, los derechos fundamentales. Son bien expresivas de esta tesis las Conclusiones del Abogado General Yves Bot al asunto Adala Bero ${ }^{33}$. Se juzgaba en él la posibilidad de que un Land alemán internase en centros penitenciarios a personas de terceros Estados en espera de expulsión, por no existir en ese Land, sí en otros, centros especializados. El problema normativo de fondo radicaba en la interpretación del artículo 16.1 de la Directiva 2008/115/CE, que excepciona la regla general de internamiento en centros especializados. Para el Gobierno alemán era factible la reclusión en una prisión si no había institución adecuada; en cambio, el Abogado General consideró que tal alternativa solo era posible en supuestos de emergencia, básicamente cuando existe un arribo masivo de inmigrantes.

Interesa subrayar que el Gobierno alemán justificó en virtud de la identidad nacional el encierro en centros penitenciarios. Dada la competencia a su favor prevista en la Constitución, los Länder, sostenía el Ejecutivo germano, habrían de ser libres para decidir de acuerdo con su situación geográfica, tamaño o número de inmigrantes, si les convenía gestionar centros propios, establecer acuerdos con otros Länder, o, en su caso, retener a los inmigrantes en cárceles (apdo. 122).

La respuesta del Abogado General a esta alegación responde al patrón clásico previo a la introducción del argumento de la identidad nacional en la retórica judicial:

«En primer lugar, el Tribunal de Justicia ha declarado de forma reiterada que un Estado miembro no puede alegar disposiciones o prácticas derivadas de su

32 En ocasiones, dada la debilidad de la alegación estatal, ni siquiera es precisa una mínima valoración de la identidad nacional. Por ejemplo, cuando el Gobierno polaco sostiene que la prohibición del comercio de cigarrillos mentolados afecta a su identidad nacional, la Abogada General Kokott, desdeña la pretensión sin más contemplaciones, Conclusiones de 23 de diciembre de 2015, República de Polonia c. Parlamento y Consejo, C-358/14, ECLI:EU:C:2015:848, apdo. 148 y 166. No obstante, se advierte en estas conclusiones que cuando se afecte la identidad nacional el juicio de subsidiariedad será más estricto.

33 Conclusiones de 30 de abril de 2014, Adala Bero, C-473/13, C-514/13 y C-474/13. 
organización federal, para justificar eventualmente el incumplimiento de las obligaciones establecidas por una directiva. Así, conforme a reiterada jurisprudencia, no incumbe a las instituciones de la Unión tener en cuenta ni pronunciarse sobre el reparto de competencias establecido por las normas institucionales de cada Estado miembro ni sobre las obligaciones que pueden incumbir a las autoridades de la República Federal y de los Estados federados, respectivamente. (apdo. 143)

Añade, además, una reflexión sobre los instrumentos de cooperación entre Länder que parece ser la razón última con la que se acomoda la particularidad territorial alemana y el cumplimiento del derecho de la Unión. Así, la estructura federal no se vería afectada en el cumplimiento de la Directiva por cuanto los Länder sin centros de internamiento pueden cooperar con los que sí disponen de ellos, satisfaciendo de manera conjunta las exigencias del Derecho de la Unión (apdo. 150 y 151). En fin, una vez más la realidad constitucional del Estado miembro es el dato que sirve para dar el contorno específico de la identidad nacional. Esta es una categoría autónoma del ordenamiento comunitario, definida en virtud de la lectura que el Tribunal de Justicia hace del derecho constitucional estatal.

Creo, sin embargo, que las Conclusiones invitan a una lectura más amplia ligada a los derechos fundamentales como criterio que limitaría la eficacia de la identidad nacional. Antes de entrar en la valoración de la explicación sostenida por el Gobierno alemán, el Abogado General realiza una reflexión sobre la finalidad de la Directiva. Destaca su esfuerzo por encuadrarla bajo el respeto a la dignidad humana (apdo. 94), de lo que deduce un principio implícito por el cual los Estados miembros no pueden dar a los inmigrantes en espera de expulsión la apariencia de delincuentes ni internarlos en centros penitenciarios (apdo. 95). Y llega a este resultado tras una detallada lectura de la jurisprudencia del TEDH relativa a las condiciones que han de respetar los centros de internamiento.

La argumentación del Abogado General es clara: la dignidad humana recogida en la Carta impone que los centros de internamiento tengan características específicas, distintas en cualquier caso a las de una cárcel. Se trata de una obligación derivada de los derechos fundamentales y que se concreta en la Directiva. Y me parece que este motivo modula la eficacia de la identidad nacional. Por tanto, de las Conclusiones cabría deducir que los derechos fundamentales de la Unión son un límite externo a la identidad nacional; no se puede apelar a esta para evitar la aplicación de aquellos.

\section{Identidad personal versus identidad nacional}

La elección del apellido propio y el de los hijos, manifestación del derecho fundamental a la intimidad/vida privada, ha dado lugar a un conjunto de sentencias que miden el potencial jurídico de nuestra categoría. Es esta una temática 
poliédrica, que cuando menos trata otros dos asuntos esenciales —el ámbito de aplicación del Derecho de la Unión y la extensión jurídica de la ciudadanía-, pero en este trabajo me voy a centrar solo en las posibilidades que ofrece la identidad nacional como justificación de las medidas nacionales que limitan la facultad individual para conformar la identidad personal a través del apellido.

El correcto encuadre de la cuestión obliga a retomar las importantes Conclusiones a García Avello ${ }^{34}$. Se juzgaba entonces la denegación por la Administración belga de la posibilidad de que dos niños con nacionalidad española y belga pudiesen alterar su apellido García Avello, por García Weber, versión que siguiendo la normativa española unía el paterno y materno. La exposición del Abogado General Jacobs centra a la perfección el problema, analizando las posibles soluciones. Entiende que no es aplicable la doctrina fijada en Kostantinidis ${ }^{35}$, que exigía una «interferencia concreta con una libertad económica específica» (apdo. 61-62), ya que la irrupción del principio de no discriminación ligado a la ciudadanía abría un nuevo panorama en el que bastaba el movimiento inter estatal sin dimensión económica. La opción por la ciudadanía, además hizo innecesario según Jacobs (al que seguirá el Tribunal de Justicia ${ }^{36}$ ) recurrir al derecho fundamental a la vida privada y familiar como premisa normativa que diese cobijo a la pretensión de los niños (apdo. 66). Es esta una acotación clave, porque de algún modo se anuncia un problema que vendrá después y que es el que a nosotros nos interesa, el de la justificación. Añade el Abogado General en el apartado 66:

«Sobre este particular, puede señalarse que el Tribunal Europeo de Derechos Humanos ha subrayado que las restricciones legales a la posibilidad de cambio de apellidos pueden estar justificadas por el interés público y que los Estados contratantes disfrutan de un amplio margen de apreciación en dicho ámbito, en particular cuando poco tienen en común las normas aplicadas en los diferentes Estados y el Derecho parece encontrarse en una fase de transición. No obstante, la existencia de un amplio margen de apreciación en el contexto del Convenio no tiene, a mi juicio, ninguna relación directa con la amplitud de margen disponible en el contexto diferente de la ciudadanía de la Unión Europea.»

Por tanto, en la aplicación de la ciudadanía, los Estados van a contar con un margen de apreciación reducido, pero además ni el Abogado General ni el Pleno del Tribunal de Justicia realizan un análisis especialmente significativo sobre las razones que podrían justificar las medidas estatales (apdo. 67 y ss. de las Conclusiones; apdo. 39 y ss. de la Sentencia).

Esta es la línea doctrinal seguida en Grunkin-Paul, en la que se ampara a un niño, que si bien ostenta solo una nacionalidad, se mueve constantemente entre

34 Conclusiones de 22 de mayo de 2003, García Avello, C-148/02, EU:C:2003:311.

35 Sentencia de 30 de marzo de 1993, Christos Kostantinidis, C-168/91, EU:C:1993:115.

36 Sentencia de 2 octubre de 2003, García Avello, C-148/02, EU:C:2003:539. 
las casas de sus padres que viven cada uno a un lado de la frontera que separa Alemania y Dinamarca ${ }^{37}$. El Tribunal de Justicia consolida la idea de que estamos ante una temática amparada en el principio de no discriminación (ahora por motivos de residencia) ligado meramente al movimiento, puesto que la ciudadanía ya no requiere interés económico. E, igualmente, el asunto se resuelve sin una discusión especialmente intensa en torno a la justificación de la normativa estatal ${ }^{38}$.

Pero las Conclusiones anuncian tangencialmente otro derrotero que más tarde cobrará relevancia ${ }^{39}$. Me refiero a la alegación que realiza el Gobierno lituano, en las que argumenta que un Estado no estaría obligado a reconocer apellidos dados a sus nacionales con arreglo a la normativa de otro Estado miembro «si dichos apellidos son incompatibles con la estructura de su idioma nacional, una parte fundamental de su herencia nacional» (apdo. 84). La Abogada General Sharpston no da importancia a esta excepción para el caso concreto, pero nos deja en el apartado 85 una escueta declaración, de nuevo referida al TEDH, que luego hará carrera en Runevič Vardyn:

«(...) No obstante, señalo que el Tribunal Europeo de Derechos Humanos ha subrayado la importancia de las consideraciones del idioma nacional en el ámbito de los nombres de persona y ha admitido que la imposición de reglas lingüísticas puede estar justificada.»

El giro importante para este trabajo va a llegar a través de Sayn-Wittgenstein. En este asunto se juzgó la posibilidad de que una ciudadana austriaca hiciese valer en su Estado de origen un cambio de apellido logrado en Alemania, fruto de su adopción por un germano y que integraba distintivos de nobleza, rasgo prohibido por la Constitución austriaca. En la búsqueda del estilo y método, me interesa sobre todo comparar el modo de hacer de la Abogada General Sharpston $^{40}$ y el de la Sala Segunda del Tribunal ${ }^{41}$.

37 Sentencia de 14 de octubre de 2008, Gunkin-Paul, C-353/06, EU:C:2008:559.

38 Alemania ha adaptado su derecho a las exigencias de la doctrina Grunkin-Paul. Su normativa actual es doble. De un lado, un conjunto de normas para reconocer el cambio de apellido de un nacional alemán que reside en otro Estado miembro. De otro, el régimen ordinario que autoriza el cambio de apellidos. En el reciente asunto Freitag se discute la situación de una persona con doble nacionalidad alemana y rumana, con residencia en Alemania, que logra su cambio de apellido en Rumanía. La autoridad alemana deniega el cambio a través del procedimiento expresamente previsto para las personas con residencia en otro Estado miembro, precisamente porque el señor Freitag reside en Alemania, subrayando que tiene abierta la vía del procedimiento ordinario. No hay en las Conclusiones del Abogado General referencia alguna a la identidad nacional. El problema versa sobre la conformidad con el Derecho de la Unión de esa dualidad de procedimientos y se analiza, dándolos por buenos, a partir del principio de efectividad y eficacia de los procedimientos, Conclusiones de 24 de noviembre de 2016, Freitag, C-541/15, EU:C:2016:902.

39 Conclusiones de 24 de abril de 2008, Grunkin-Paul, C-353/06, EU:C:2008:246.

40 Conclusiones de 14 de octubre de 2010, Sayn-Wittgenstein, C-208/09, EU:C:2010:608.

41 Sentencia de 22 de diciembre de 2010, Sayn-Wittgenstein, C-208/09, EU:C:2010:806. 
La primera da valor sin más a la prohibición constitucional como razón legítima que aplicada proporcionadamente limitaría la libre circulación de ciudadanos europeos. Así, evitar la resurrección de castas privilegiadas justificaría la prohibición de apellidos que «claramente derivan de auténticos títulos nobiliarios y que pueden ser percibidos como tales» (apdo. 62 y 63). En cambio, a la Sala no le basta con que exista una prohibición constitucional, sino que ha de integrarse en el Derecho de la Unión a través de la cláusula de orden público; pero esta cláusula está ahora precedida por la intelección de la Ley de abolición de la nobleza «como elemento de la identidad nacional» (apdo. 83).

En definitiva, Sayn-Wittgestein nos advierte de que la realidad constitucional estatal justifica limitaciones a la libre circulación. El impulso continúa con Runevič Vardyn, en el que se juzga el derecho de una mujer lituana de origen polaco a recibir sus certificados de nacimiento y matrimonio en forma escrita polaca y no con la grafía lituana. De nuevo interesa contrastar las Conclusiones ${ }^{42}$ con la Sentencia ${ }^{43}$, pues muestran caminos divergentes, en los que la segunda, a diferencia de la primera, da peso a la identidad nacional.

La solución propuesta por el Abogado General Jääskinen aborda la justificación dando una relevancia menor a la identidad nacional, casi de pasada y a mayor abundamiento, ligándola a la protección de la lengua oficial (apdo. 88). El centro de gravedad de su solución entra en diálogo directo con la jurisprudencia del TEDH, que ha reconocido un amplio margen a los Estados para la determinación de las reglas patronímicas, sin considerar lesivas situaciones comparables a la que se juzgaba en Runevič Vardyn (apdo. 79). Sin embargo, retoma la posición del Abogado General en García Avello, yugulando el margen de apreciación de los Estados precisamente porque la cuestión tiene que ver con la ciudadanía, contexto distinto al que afronta el TEDH (apdo. 100).

En la Sentencia, por el contrario, llama la atención el uso de la identidad nacional. No se conjuga de la mano del orden público, que ni siquiera aparece entre los argumentos utilizados. Pero tampoco se aplica la identidad nacional de modo aislado, sino que interviene a la par que un derecho fundamental y otras disposiciones de derecho originario. Afirma el Tribunal de Justicia en el apartado 86:

«En efecto, a tenor del artículo 3 TUE, apartado 3, párrafo cuarto, así como del artículo 22 de la Carta de los Derechos Fundamentales de la Unión Europea, la Unión respetará la riqueza de su diversidad cultural y lingüística. Conforme al artículo 4 TUE, apartado 2, la Unión respetará asimismo la identidad nacional de sus Estados miembros, de la que también forma parte la protección de la lengua oficial nacional del Estado.»

42 Conclusiones de 16 de diciembre de 2010, Runevič Vardyn, C-391/09, EU:C:2010:784.

43 Sentencia de 12 de mayo de 2011, Runevič Vardyn, C-391/09, EU:C:2011:291. 
Con todo, el asunto Bogendorff es un buen ejemplo del creciente peso de la identidad nacional. Su similitud con Sayn-Wittgenstein es evidente, aunque la negativa de la Administración alemana a aceptar un apellido que ha ganado su alcurnia en el Reino Unido se justifica en el principio de igualdad, sin que exista, como en Austria, una prohibición constitucional expresa de los usos nobiliarios. Una vez más comparar las Conclusiones ${ }^{44}$ y la Sentencia ${ }^{45}$ es muy enriquecedor para intentar distinguir los perfiles propios de la identidad nacional, puesto que una y otra utilizan el orden público como criterio normativo, las primeras a secas, y la segunda con el añadido de la identidad nacional, lo que genera resultados distintos.

El Abogado General Wathelet se aproxima al problema reforzando el carácter restrictivo del orden público, del que considera:

«(...) [las] normas y [los] valores cuya inobservancia no cabe concebir en el ordenamiento jurídico del foro de reconocimiento y de ejecución porque semejante inobservancia sería inaceptable desde el punto de vista de un Estado de Derecho, libre y democrático» (apdo. 99); «(...) Esto implica que, para que una norma se considere de orden público, debe tratarse de una norma imperativa tan fundamental para el ordenamiento jurídico afectado que no se pueda concebir ninguna excepción en el contexto del asunto controvertido» (apdo. 100).

Esto le lleva a entender que la prohibición de reconocer un apellido de tintes nobiliarios adquiridos en otro Estado miembro se excluye para el caso alemán del orden público, dado que a diferencia de Sayn-Wittgenstein: «el ordenamiento jurídico alemán, y en particular el artículo 109, párrafo tercero, de la Constitución de Weimar, no establece una prohibición estricta de mantener los títulos nobiliarios» (apdo. 101).

La Sentencia, como ya se ha señalado, une al orden público la identidad nacional (apdo. 64-65), y esta parece ser la razón que conduce al Tribunal de Justicia a integrar dentro de la primera categoría la normativa constitucional alemana, pese a que no se formula como una prohibición expresa de los títulos nobiliarios. Es decir, mientras que para el Abogado General la realidad constitucional, al no contener una prohibición en la Constitución, no encajaría en el concepto de orden público, para el Tribunal, este, leído a la luz de la identidad nacional, sí daría cabida a esa realidad constitucional.

\section{La lengua}

La lengua oficial es una de las características que distinguen al Estado soberano. Es inevitable, por tanto, que entre en tensión con una estructura transnacional

44 Conclusiones de 14 de enero de 2016, Bogendorff, C-438/14, EU:C:2016:11.

45 Sentencia de 2 de junio de 2016, Bogendorff, C-438/16, EU:C:2016:401. 
como la Unión, ya sea en su propia organización interna ${ }^{46}$ o en el desarrollo del paradigma de la libre circulación. La cita textual del apartado 86 de la Sentencia al asunto Runevič Vardyn, recogida en el epígrafe anterior, muestra la contundencia del Tribunal de Justicia en la consideración de «la protección de la lengua oficial nacional del Estado» como elemento que integra la identidad nacional.

Es este un viejo problema anterior a nuestra categoría. Merece la pena traer a colación las Conclusiones del Abogado General Darmon a Groener en 1989, que ya enmarcan perfectamente el problema que luego se acuñara en el término identidad nacional. Se enjuiciaba la conformidad con la libre circulación de trabajadores de una normativa irlandesa que exigía para el acceso a un puesto permanente dentro de un centro público de enseñanza, concretamente el de profesora de dibujo, acreditar el conocimiento del irlandés. El Abogado General destila a la perfección la esencia del dilema en el apartado 16:

«Se trata, en efecto, y con ello llegamos al corazón mismo de la discusión, de trazar la línea divisoria que separa las competencias comunitarias de las estatales, así como de valorar si la defensa y la promoción de una lengua pueden llegar a desconocer las exigencias impuestas por el Derecho comunitario.»

Nos advierte de que este interrogante, al referirse a la promoción de una lengua minoritaria, alcanza al «corazón mismo de la identidad cultural» ${ }^{47}$ : «Corresponde, por consiguiente, a la Comunidad decidir si esta o aquella lengua tienen o no derecho a sobrevivir?» (apdo. 19). Y también aparece, anticipando los elementos que pivotan en torno a la identidad nacional, la referencia a la norma suprema del Estado como uno de sus elementos distintivos ${ }^{48}$. Afirma Darmon:

«El hecho de que la propia Constitución (las cursivas son del Abogado General) reconozca el irlandés como lengua oficial, da fe, en el caso de autos, de la voluntad del Estado irlandés de reconocer a la defensa de este patrimonio una importancia de primer rango.» (apdo. 20); «A partir del momento en que una Constitución - es decir, el conjunto de valores superiores a los que una nación declara solemnemente adherirse- reconoce la existencia de dos lenguas oficiales sin limitar su utilización a partes determinadas de su territorio o a ciertas materias, todo ciudadano tiene derecho a que se le imparta docencia en las dos lenguas» (apdo. 21).

46 En el uso de las lenguas dentro de la Administración de la Unión, la selección de unas sobre otras se ha convertido en cuestión de naturaleza constitucional. El debate une a la identidad nacional, el multilingüismo reconocido en el artículo 22 de la Carta, véase por ejemplo, Conclusiones de 21 de junio de 2012, República Italiana c. Comisión, C-566/10 P, EU:C:2012:752, apdo. 86.

47 La Sentencia destaca la promoción de una lengua «como medio de expresión de la identidad y cultura nacionales», Sentencia de 28 de noviembre de 1989, Groener, C-379/87, EU:C:1989:599, apdo. 18.

48 La Sentencia transcribe directamente la Constitución irlandesa, ibid., apdo. 17. 
Desde estas premisas, no sorprende que el Tribunal de Justicia haya incorporado de modo natural la protección de las lenguas oficiales en el seno de la identidad nacional; difícilmente se encuentra un elemento que encaje mejor en la categoría. Pero tal seguridad no disuelve el conflicto latente entre la lengua nacional (o lenguas oficiales) y cualquier proyecto de naturaleza supraestatal. Un buen ejemplo lo encontramos en Anton Las, asunto en el que se evalúa la normativa belga que impone la redacción de los contratos de trabajo en neerlandés cuando la empresa tenga sus actividades en la región lingüística neerlandesa. Concretamente, se trataba de un contrato de alta dirección con una multinacional, que estaba redactado en inglés.

Tanto las Conclusiones ${ }^{49}$ como la Sentencia $^{50}$ reiteran sin lugar a dudas que la definición de la lengua oficial se incluye en la identidad nacional. Veamos, por ejemplo, la contundencia del Abogado General:

«(...) el concepto de identidad nacional, que deben respetar las instituciones de la Unión en virtud del artículo 4 TUE, apartado 2, incluye los aspectos lingüísticos del ordenamiento constitucional de un Estado miembro que definen, en particular, la lengua oficial o las diversas lenguas oficiales del Estado así como, en su caso, las subdivisiones territoriales en las que se utilizan las mismas. (37) De este modo, el concepto de «identidad nacional» tiene que ver con las elecciones que se hacen en cuanto a las lenguas utilizadas a escala nacional, o incluso regional (...)» (apdo. 59 Conclusiones).

Los términos del debate, por tanto, se centran en dilucidar la intensidad justificativa de nuestra categoría cuando ampara el régimen que los Estados dan a las lenguas oficiales. A priori, la Sentencia al asunto Runevič Vardyn podría hacernos pensar en su solidez, capaz de imponerse en el conflicto que la enfrentaba a la facultad individual de elegir el apellido, manifestación del derecho fundamental a la vida privada. En mi opinión, Anton Las rebaja las expectativas a través de dos modulaciones significativas.

En primer lugar, realiza una distinción respecto a Groener:

«(...) No puede sostenerse que la simple redacción de contratos de trabajo de carácter transfronterizo en una lengua distinta al neerlandés por parte de algunas empresas con sede en Flandes pueda amenazar el florecimiento del uso de esta última lengua. No puede decirse lo mismo cuando lo que está en juego en una relación laboral es la transmisión de conocimientos, como ocurre en la enseñanza escolar o universitaria, ámbito que afecta a la defensa de la identidad cultural de un Estado miembro y que justifica que pueda exigirse a un candidato la posesión de determinadas competencias lingüísticas.» (apdo. 61); «En particular, no puedo percibir

49 Conclusiones de 12 de julio de 2012, Anton Las, C-202/11, EU:C:2012:456

50 Sentencia de 16 de abril de 2013, Anton Las, C-202/11, EU:C:2013:239, apdo. 26. 
cuál es el peligro que puede correr la lengua neerlandesa por el hecho de que se utilice otra lengua en un contrato de trabajo que, como el del procedimiento principal, haya sido celebrado entre un trabajador que hace uso de su libertad de circulación y un empleador que es una sociedad perteneciente a un grupo de ámbito internacional» (apdo. 75).

Me parece que de las acotaciones de Jääskinen se deduciría que realmente no es la lengua oficial lo que se protege a través de la identidad nacional, sino, en verdad, la identidad cultural. De este modo, para que una regulación lingüística se considere obstáculo justificable frente a las libertades fundamentales es preciso que tenga como fin primordial la defensa de una lengua, más allá de su uso común ${ }^{51}$. Y esto solo ocurriría, siguiendo las observación de Darmon en Groener (apdo. 19), cuando la lengua es minoritaria ${ }^{52}$; o bien, tal y como indica Jääskinen, porque su uso se integra en la estructura educativa. Fuera de estos supuestos, en los términos de este Abogado General, la identidad nacional en relación con la lengua no puede conducir a un «monolingüismo exclusivo, que implique que en ningún caso puedan utilizarse con carácter alternativo las lenguas de los demás Estados miembros en un determinado ámbito.» (apdo. 64) ${ }^{53}$.

Es la segunda matización la que muestra de modo palmario el choque inevitable entre lengua nacional (o lenguas nacionales) con proceso de integración supranacional. Afirma el Abogado General:

«Sin embargo, debe respetarse la libertad contractual, en el sentido de que el trabajador puede aceptar la utilización en su lugar de trabajo de una lengua distinta de la suya y de la que se utilice localmente, sobre todo tratándose de una relación laboral enmarcada en un contexto internacional, como expresamente contempla la resolución de remisión. Considero que, en el ámbito de la Unión, los empresarios deberían tener la facultad de fijar una lengua de trabajo común para su personal, lengua que, en una empresa establecida en varios Estados miembros, puede ser diferente de la que se emplea a escala regional o nacional (...)» (apdo. 63); «Estimo que el proyecto de integración europea pierde parte de su sentido si los Estados

51 El uso común de la lengua, no obstante, también puede justificar obstáculos a la libre circulación. Por ejemplo, puede ser una exigencia para el desempeño de una profesión sanitaria, en la medida que protege al consumidor asegurándole la comunicación con el prestador de servicios, Conclusiones de 19 de mayo del AG Mischo, Haim, C-424/97, EU:C:1999:253, apdo. 106 y ss. Pero una vez que la profesión ha sido armonizada — la de abogado — los controles ex ante de naturaleza lingüística perderían validez; no así los controles a posteriori de naturaleza deontológica, Sentencia de 19 de septiembre de 2006, Comisión c. Gran Ducado de Luxemburgo, C-139/95, EU:C:2006:588, apdo. 44 y ss.

52 Lo cual no excluye, sin embargo, la obligación de extender a nacionales de otro Estado miembro las medidas de protección lingüística de una minoría; por ejemplo, que los alemanes y austriacos puedan defenderse procesalmente en alemán dentro de las zonas de Italia donde sus residentes italianos poseen ese derecho, Sentencia de 24 de noviembre de 1998, Bickel/Franz, C-274/96, EU:C:1998:563, apdo. 27.

53 El «monolingüismo» (la imposición de una lengua sin dar cabida a otras alternativas) ha sido censurado por el Tribunal de Justicia en los etiquetados de mercancías, véase Sentencia de 12 de septiembre de 2000, Yannik Geffroy, C-366/98, EU:C:2000;430, apdo. 28. 
miembros pueden imponer a los agentes económicos, como los empresarios y los trabajadores, el uso de una determinada lengua, en una proporción que sobrepase las restricciones a la libertad contractual estrictamente necesarias para alcanzar objetivos de interés general (...)» (apdo. 71).

Es importante, contrastar esta idea con las apreciaciones realizadas en el epígrafe anterior en relación a la determinación del apellido (y en parte a las que se harán posteriormente respecto a la libertad religiosa en el trabajo). En ambos casos, por más que el centro del debate sea la limitación de una libertad fundamental, los perfiles desvelan un interés que trasciende lo económico para entrar de lleno en la autonomía individual (la definición de la identidad personal a través del apellido; la elección del idioma en las relaciones laborales). El problema señala el difícil equilibrio entre la identidad nacional y la identidad individual; en fin, vino viejo en nuevos odres. Pero lo significativo son las claves de esa tensión clásica que ahora se enmarca en un contexto supranacional. En concreto, ya hemos visto como Jääskinen la formula agarrándose a la libertad contractual, que sería así el escudo bajo el que se protege lo transnacional, en concreto, la economía globalizada. Es imposible evitar una comparación histórica. Si a lo largo del siglo XIX, la libertad contractual fue la lanza utilizada para desmontar los lastres del feudalismo, ahora pretende ser un límite frente al Estado soberano y su identidad nacional.

\section{4. ¿La religión?}

La identidad nacional es una categoría que todavía está explorando sus posibilidades normativas. Por ello, con un acento especulativo querría detenerme en la comparación de dos Conclusiones, Samira Achbita ${ }^{54}$ y Asma Bougnaoui ${ }^{55}$, de mayo y julio de 2016 (que a la entrega de este trabajo todavía no ha recibido sentencia). En ambas se valora la discriminación por motivos de religión, en especial a la luz de Directiva 2000/78/CE, del Consejo, de 27 de noviembre de 2000, relativa al establecimiento de un marco general para la igualdad de trato en el empleo y la ocupación. En el primer caso se juzga la licitud del despido de una recepcionista por negarse a trabajar sin pañuelo; la empresa en su reglamento interno imponía el principio de neutralidad religiosa y política. En el segundo se decide también sobre la validez del despido de una ingeniera que renuncia a desvestirse el pañuelo cuando está en contacto con los clientes; en el proceso de contratación se le había hecho saber a la empleada que no siempre podría llevar esa prenda.

54 Conclusiones de 31 de mayo de 2016, Samira Achbita, C-157/15, EU:C:2016:382.

55 Conclusiones de 13 de julio de 2016, Asma Bougnaoui, C-188/15, EU:C:2016:553. 
La laicidad como elemento integrante de la identidad nacional solo va a aparecer en las primeras Conclusiones, las de la Abogada General Kokott. Sin embargo, creo que la cuestión es del máximo interés porque en los dos casos late el problema general que enmarca nuestra categoría, la geografía adecuada de los temas netamente constitucionales. Mi atención se centrará en señalar la estrategia que utilizan las Abogadas Generales para afrontar este dilema, a sabiendas de que el uso de los símbolos religiosos, en especial los minoritarios, más aún sí son islámicos, es uno de los debates de alto voltaje que ocupa a muchos de los Estados de la Unión, al TEDH y que ahora ha arribado a la Unión.

En Samira Acbbita la respuesta pasa por la calificación de la discriminación: si se considera directa, entonces su descargo (en verdad, del trato distinto) solo podrá sustentarse sobre los presupuestos específicos dispuestos en la Directiva; en cambio, si se toma como una discriminación indirecta, la Directiva abre la justificación a cualquier objetivo legítimo que se aplique de manera proporcionada. Es obvio que según la valoración jurídica que se dé al despido por vestir el pañuelo, el Estado miembro (y sus empresarios) tendrán un mayor margen de maniobra para articular el conflicto constitucional.

Kokott considera que estamos ante una discriminación indirecta ${ }^{56}$. Como ya se ha dicho, esta decisión genera un juicio de proporcionalidad en el que el punto de partida, el objetivo legítimo, es mucho más amplio (si bien ella se concentra en los que expresamente se prevén para la discriminación directa). Así las cosas, Kokott cursa en detalle los hitos típicos de la proporcionalidad (adecuación, apdo. 100-103; necesidad, apdo. 104-111; perjuicio no excesivo para el trabajador, apdo. 111-124) y sin solución de continuidad, añade en el apartado 125:

«Para concluir, en la interpretación y aplicación del principio de igualdad de trato debe respetarse también la identidad nacional de los Estados miembros, inherente a las estructuras fundamentales políticas y constitucionales de éstos (artículo 4 TUE, apartado 2). En referencia a una cuestión como la que aquí nos ocupa, esto puede significar que en Estados miembros como Francia, en que el laicismo adquiere rango constitucional y, por tanto, se plasma en la convivencia social, el uso de símbolos religiosos visibles puede ser objeto de restricciones más estrictas, incluso en el sector privado y, en general, en la vida pública, que en otros Estados miembros cuyo

56 Quiero mantener la atención en la identidad nacional, pero no me resisto a citar textualmente los argumentos de la Abogada General en relación al tipo de discriminación: «En definitiva, en el presente caso estamos únicamente ante una diferencia de trato entre los trabajadores que desean expresar activamente una determinada convicción (ya sea de índole religiosa, política o filosófica) y sus compañeros que no sienten esa necesidad. Pero esa diferencia de trato no constituye ningún «trato menos favorable» directo y vinculado específicamente a la religión» (apdo. 53); «No obstante, dado que tal norma en la práctica puede afectar a las personas de determinadas religiones o convicciones (en el presente caso, a las trabajadoras de confesión musulmana) de manera más acusada que a otros trabajadores, no se puede descartar que exista una discriminación indirecta [artículo 2, apartado 2, letra b), de la Directiva 2000/78], sin perjuicio de la posibilidad de una justificación.» (apdo. 57). 
ordenamiento constitucional establezca otras prioridades o ponga menos énfasis a este respecto.»

Idea que se refuerza en el apartado 127, cuando declara a modo de conclusión:

«En último término, no obstante, incumbe al órgano jurisdiccional remitente buscar un equilibrio justo entre los intereses contrapuestos teniendo en cuenta todas las circunstancias relevantes del caso concreto, en particular el tamaño y la vistosidad del símbolo religioso, el tipo de actividad de la trabajadora y el contexto en que debe desarrollarla, así como la identidad nacional de Bélgica.»

Estamos ante una doctrina balbuciente y conviene ser prudente, pero los apartados citados abren una doble perspectiva. Cabe pensar que la identidad nacional se activa al terminar de evaluar la proporcionalidad de la medida que postula un trato distinto. Así, nuestra categoría sería un criterio de aplicación posterior, que a diferencia del principio de proporcionalidad, ofrece una magnitud sustancial para el contraste de la actuación supuestamente discriminatoria. Es decir, la identidad nacional no es el objetivo legítimo que ha de justificar la medida, que en cualquier caso habrá de ser proporcionada, sino que opera después, cuando ya se ha verificado la proporcionalidad. Este tipo de análisis conduce a una situación contradictoria, puesto que podría ocurrir que una decisión que no persigue un objetivo legítimo o que haciéndolo incurre en desproporcionalidad, sin embargo, es lícita en razón de la identidad nacional. De este modo, medidas que no salvan el canon de la proporcionalidad, encuentran cobijo bajo la premisa sustantiva de la identidad nacional.

Esta dificultad ilumina el sentido de la posición de Francia, para quien la identidad nacional impediría la aplicación de la Directiva (apdo. 31-32), opción que obviamente hubiese evitado la paradoja que resulta de las Conclusiones. Pero la Abogada General rechaza la propuesta afirmando:

«(...) Es la aplicación (las cursivas son de la Abogada General) de la Directiva lo que en ningún caso puede menoscabar la identidad nacional de los Estados miembros. Por lo tanto, la identidad nacional no limita el ámbito de aplicación de la Directiva en sí mismo, sino que debe ser tenida debidamente en cuenta al interpretar el principio de igualdad de trato que ésta consagra, así como las justificaciones de las eventuales diferencias de trato. La propia Francia ha reconocido, por cierto, en la vista oral ante el Tribunal de Justicia, que tal forma de proceder es una forma viable de proteger la identidad nacional.» (apdo. 32)

Es posible, por otro lado, una valoración distinta de los apartados 125 y 127, de manera que la identidad nacional no sería una premisa normativa separada del principio de proporcionalidad, sino un elemento adicional dentro de este. Junto a los pasos típicos —adecuación, necesidad y proporcionalidad en sentido estricto- habría de añadirse un cuarto, por lo que tratos aparentemente 
discriminatorios serían proporcionados al encarnar la identidad nacional de un Estado miembro.

Tal solución no está exenta de oscuridades. Se ha de recordar que el principio de proporcionalidad debe su éxito a la desustancialización que conlleva. Permite a los tribunales abandonar el esfuerzo de determinar el contenido (esencial) de un derecho, para limitarse a valorar si la norma es razonable. Introducir la identidad nacional dentro de ese juicio quiebra a todas luces su lógica, pues incorpora una categoría que ha de construirse materialmente, valorando si una decisión integra o no la identidad nacional de un Estado.

Sea como fuere, la irrupción de la identidad nacional refleja el esfuerzo de Kokott por dar espacio a los Estados miembros en un asunto de evidente magnitud y singularidad constitucional. Esa voluntad se presenta con contundencia en el apartado 99, en la que apela al margen de apreciación de los jueces nacionales en conexión con la jurisprudencia del TEDH:

«En un caso como el presente, la prueba de proporcionalidad es un asunto delicado en que nuestro Tribunal de Justicia, adhiriéndose a la práctica del TEDH en relación con los artículos 9 y 14 del CEDH, debería otorgar a los organismos nacionales (especialmente a los órganos jurisdiccionales) un cierto margen de apreciación, del que éstos han de hacer uso dentro de un escrupuloso respeto de las exigencias del Derecho de la Unión. No es absolutamente necesario a este respecto imponer desde Luxemburgo una solución uniforme para toda la Unión Europea. A mi parecer, basta con que el Tribunal de Justicia le señale al órgano jurisdiccional remitente todos los puntos de vista relevantes que ha de tener en cuenta al examinar la proporcionalidad, y debe cederle a éste, por lo demás, la ponderación concreta de los intereses en juego.»

El dilema en Asma Bougnaoui es idéntico: ¿quién decide el papel de la religión en el ámbito laboral? Pero Sharpston, que no se inclina en favor de la deferencia a los Estados, toma una estrategia dogmática distinta. Primero cierra la puerta a la identidad nacional con un razonamiento formal, en parte derivado del rigor del principio dispositivo en materia procesal:

«Reconozco que, en este contexto, las relaciones exactas entre la Directiva y la normativa nacional, incluida las disposiciones de Derecho constitucional, pueden dar lugar a debates complejos. Con esto, quiero dejar claro que no acepto ni rechazo la postura del Gobierno francés en cuanto a la aplicabilidad del principio de laicidad al empleo en el sector público en el marco de la Directiva 2000/78. Las demás partes que han presentado observaciones al Tribunal de Justicia en el presente asunto no han abordado este tema y, por consiguiente, las cuestiones que se habrían o podrían haberse planteado no han sido objeto de un debate detallado. En consecuencia, en las observaciones que siguen me limitaré exclusivamente al sector privado. (apdo. 81)»

Esta salida no deshace la esencia del problema, que es determinar si la laicidad excepciona la aplicación del Derecho de la Unión. Simplemente se coge otro camino 
que queda perfectamente formulado en los apartados 58-67 bajo la rúbrica «Diferencias entre un enfoque basado en restricciones y un enfoque basado en discriminación». La empresa propone que la cuestión se solvente en la lógica del TEDH (que la Abogada General expone con cierto detalle). Quiere así que el juego dogmático se desenvuelva en el campo de un derecho fundamental — la libertad religiosa - y en los términos propios del TEDH, por lo que cabrán intervenciones sobre el derecho que persigan un objetivo legítimo de forma proporcionada. Además, en el debate se ha hecho evidente que el TEDH ha reconocido un amplio margen de apreciación a los Estados en la ordenación del uso de símbolos religiosos. Sharpston, consciente de las consecuencias a las que conduce ese problema, lo descalifica como «simplista» (apdo. 61) y opta por acotar la decisión en la elección binaria entre discriminación directa, que, como ya hemos visto es excepcionada solo en supuestos muy limitados, y la indirecta, modulable por mor de todo tipo de objetivo legítimo.

En definitiva, la Abogada General afronta la cuestión separando la libertad religiosa del principio de discriminación por motivos religiosos. Técnicamente, el segundo tendría un contenido protegido mayor que el primero, en tanto que serían menos las razones que justificarían su modulación. Se aparta así, con invocación expresa del artículo 52.2 de la Carta de la jurisprudencia del TEDH (apdo. 64), que no da un tratamiento autónomo al principio de igualdad cuando confluye con otro derecho. Sin duda, un camino dogmático innovador destinado en parte a comunitarizar el problema, cerrando el margen de apreciación del Estado, o la eficacia de su identidad nacional.

\section{A MODO DE CONCLUSIÓN}

\section{La identidad nacional en cuanto que categoría jurisdiccional ha llegado para quedarse ${ }^{57}$}

Los Estados miembros la usan como un elemento más de oposición a la aplicación del Derecho de la Unión y el Tribunal, sobre todo sus Abogados Generales,

57 Una lectura muy sugestiva propone que la protección jurisdiccional de esta categoría ha pasado por tres fases: una primera de reconocimiento implícito, que se correspondería con la ya clásica reacción de los Tribunales Constitucionales alemán e italiano en defensa de los derechos fundamentales; otra, a lo largo de los noventa, en el que se deja un margen de discrecionalidad a los Estados miembros; y la actual, dominada por el principio de proporcionalidad, RoDIN, S., «National Identity and Market freedoms after the Treaty of Lisbon", Croatian Yearbook of European Law and Policy, n. ${ }^{\circ}$ 7, 11-41, 2011, pp. 20 y ss. Se trata, sin embargo, de una visión que toma la identidad nacional en sentido muy amplio y deja a un lado la crucial cuestión de por qué la identidad nacional/constitucional en sentido estricto ha cobrado en los últimos años un especial interés. Diversos autores consideran que esta circunstancia se debe a que la identidad nacional ha sustituido en términos narrativos a la soberanía, SAiz Arnaiz, A., y Alcoberro Llivina, C., «Introduction. Why Constitutional Identity Suddenly Matters: A Tale of Brave States, a Mighty Union and the Decline of Sovereignty», p. 4; y ToniatTi, R., «Sovereignty Lost, Constitutional Identity Regained», pp. 54 y ss., ambos trabajos en National Constitutional Identity and European Integration, ed. Saiz Arnaiz y Alcoberro Livina, Intersentia, 2013. 
han asumido la responsabilidad de intentar darle un sentido operativo ${ }^{58}$. No es este un dato baladí, si lo comparamos por ejemplo con el principio de subsidiariedad, que llamado a cumplir una función similar, ha dado escasos réditos en la resolución de controversias. Con todo, la litigiosidad de la identidad nacional no debería debilitar su potencial en los procesos políticos. Es en la creación de normas donde mejor se pueden ajustar las singularidades de los Estados miembros ${ }^{59}$.

\section{El uso de la identidad nacional ha tenido consecuencias evidentes en la articulación de la disputa centro/periferia}

Su alegación en defensa de la autonomía territorial ha propiciado un principio general por el cual los Estados miembros, en virtud de su organización descentralizada, pueden crear normas que de otro modo serían obstáculos a las libertades fundamentales. Es plausible incluso hablar de una presunción en favor de la licitud de medidas adoptadas por entes subestatales, salvo cuando afectan a los derechos fundamentales. Una conclusión similar se alcanza si la identidad nacional reivindica la singularidad lingüística; aquí también se refuerza la normativa estatal, que solo cede si esconde en verdad la preferencia por el idioma mayoritario de un Estado miembro.

Por otro lado, en el ámbito de la elección de los apellidos, esto es, en un espacio sensible al libre desarrollo de la personalidad, la identidad nacional ha causado un giro significativo. De una jurisprudencia que ceñía las potestades del Estado miembro, en una visión alternativa a la que había elaborado el TEDH, se ha pasado a una doctrina más cercana a la de este Tribunal, que amplía el margan de acción estatal.

\section{La identidad nacional posee un espectro de actuación limitado}

La categoría no sirve para dar cobijo a cualquier medida estatal que tenga una cierta relevancia o encarne el interés general, sino que ha de tener una conexión

58 Y la doctrina sigue encontrando utilidades, por ejemplo, la identidad nacional sería un límite al control de comunitariedad por parte de los jueces ordinarios de la decisión de un Tribunal Constitucional, UGARTEMENDía ECEIZABARRENA, J.I., «El control de comunitariedad de las resoluciones jurisdiccionales y el límite de la identidad constitucional», Revista Española de Derecho Europeo, n. ${ }^{\circ}$ 59, 13-43, 2016, p. 41,

59 No olvidemos que hasta el Tratado de Lisboa la identidad nacional carecía de protección jurisdiccional. Mary Dobbs sostiene que el peso político de la identidad nacional ya se hizo notar en la negociación del Tratado de Lisboa, como bien reflejan diversos protocolos, por ejemplo, el suscrito por el Reino Unido y Polonia sobre la aplicación de la Carta (Protocolo 30), el número 35 relativo a la prohibición del aborto por la Constitución irlandesa; o las reservas danesas atinente la aplicación del Título V de la Carta, Protocolo número 22, véase DobBs, M., «Sovereignty, Article 4(2) TEU and the Respect of National Identities: Swinging the Balance of Power in Favour of the Member States? ", Yearbook of European Law, vol. 33, n. ${ }^{\circ}$ 1, 298-334, 2014, pp. 316 y ss. 
constitucional. Este matiz la distingue de otros conceptos afines como el de orden público o el de exigencias imperativas, aunque la yuxtaposición con el primero todavía es habitual. Sin embargo, mientras que el orden público está confinado en el juego de las libertades fundamentales, la identidad nacional se abre a otros supuestos.

Todo apunta a que los derechos fundamentales de la Constitución estatal no se integran en la categoría de identidad constitucional. Las posibles divergencias entre derechos fundamentales (de la Unión y de la Constitución) se estructuran ahora en los artículos 51 y siguientes de la Carta, sin que nuestra categoría a estudio aporte nada nuevo. Formalmente es posible hablar de una intersección entre el artículo 4.2 del TUE y el 53 de la Carta, derivada de la lectura complementaria entre Omega y Melloni ${ }^{60}$. El primero protegería a un derecho fundamental de tal peso que delimita la identidad nacional, mientras que el segundo ampararía la mayor protección de un derecho fundamental en el contexto de una coincidencia de derechos con la Carta.

Pero en la práctica, la identidad nacional ha servido para cubrir prohibiciones que derivan de una disposición que reconoce derechos fundamentales. Por ejemplo, en Omega no se protege el derecho fundamental a la dignidad humana; se justifica la prohibición impuesta por una autoridad pública, derivada del deber de proteger la dignidad humana. Y esta acotación sirve a su vez para denotar que el verdadero potencial de la identidad nacional reside en su valor para ajustar las prohibiciones constitucionales, esto es, esas particulares y escasas disposiciones recogidas en la norma suprema cuyo fin es vedar una conducta de los ciudadanos (utilizar apellidos nobiliarios, ignorar una lengua oficial o quebrar la neutralidad religiosa).

\section{La identidad nacional es una categoría autónoma del Derecho de la Unión}

Pero, al mismo tiempo, es un mandato normativo que obliga al Tribunal de Justicia a interpretar la realidad constitucional del Estado miembro que la alega.

De la práctica seguida hasta ahora han de extraerse cuatro criterios.

1. Implica una carga procesal.

Corresponde al Estado miembro invocar la identidad nacional y justificar que un elemento goza de la necesaria singularidad constitucional. Esto, lógicamente, no significa que la categoría sea subjetiva, pues en

60 Esta sería la sugerente posición de Torres Pérez, A., «Constitutional Identity and Fundamental Rights: the intersection between articles 4(2) TEU and 53 Charter», en National Constitutional Identity and European Integration, ed. Saiz Arnaiz y Alcoberro Livina, Intersentia, 2013. 
última instancia el Tribunal de Justica valora la bondad de la argumentación estatal. Pero sí que se trata de una actuación sui géneris, más parecida a un peritaje que a una alegación, dado que el Tribunal de Justicia ha de ser instruido sobre un ordenamiento del que no es experto ${ }^{61}$ y de ahí que la construcción del Estado miembro deba tener una relevancia prioritaria $^{62}$.

2. ¿Qué método sigue el Tribunal de Justicia para integrar una singularidad dentro de la identidad nacional?

Este es el punto más oscuro. Suele construirse de un modo un tanto apodíctico. Ciertamente, no es nada nuevo para el Tribunal de Justicia trabajar sobre la realidad constitucional de un Estado miembro, si bien la identificación de singularidades exige una tarea distinta a la reelaboración de las tradiciones constitucionales. En cualquier caso, puede deducirse una tendencia en la jurisprudencia: la identidad nacional ha de tener una conexión con el derecho constitucional en sentido amplio (no solo con la norma constitucional), pero no basta con que se recoja en la Constitución, sino que ha de reflejar una decisión fundamental ${ }^{63}$.

En este sentido, al margen del problema que plantea la religión y que indiscutiblemente abre un horizonte novedoso, ha de reconocerse que el Tribunal de Justicia había logrado encapsular la identidad nacional en tres escenarios —autonomía territorial, lengua ${ }^{64}$ y prohibiciones

61 Sería una legitimidad antes socrática (solo sé que no sé nada) que epistémica, Ferreres Comella, V., «El Tribunal de Justicia de la Unión Europea y el principio constitucional de supletoriedad del derecho estatal: un juicio socrático en Luxemburgo», Revista Española de Derecho Constitucional, n. ${ }^{\circ}$ 103, 333-353, 2015, p. 335.

62 vON Bogdandy, A., y Schill, S., «Overcoming absolute primacy: respect for national identity under the Lisbon Treaty», Common Market Law Review, vol. 48, n. ${ }^{\circ}$ 5, 1417-1454, 2011, p. 1429.

63 Este conclusión inferida de la jurisprudencia del Tribunal de Justica evoca de manera consciente la schmittiana distinción entre Constitución y Ley constitucional, Schmitr, C., Teoría de la Constitución, trad. F. Ayala, Alianza Universidad, 1982, pp. 37 y ss. Y si esta evocación es correcta, entonces aquí radicaría el punto de conexión conceptual entre la identidad nacional del Derecho de la Unión y la identidad constitucional del Derecho alemán, véase Azpitarte Sánchez, M., op. cit., n. ${ }^{\circ}$ 15, p. 953 (nota 16); y, de un modo más extenso, Azpitarte SÁnchez, M., El Tribunal Constitucional ante el control del Derecho comuntario derivado, Civitas, 2002, pp. 32 y ss.

Es oportuno reflexionar sobre el uso indistinto de los conceptos de identidad nacional e identidad constitucional, puesto que existe una diferencia semántica. Konstadinidis sugiere una distinción: la identidad nacional es la expresión de un pueblo soberano; la identidad constitucional es la manifestación constitucionalmente normativa de ese pueblo soberano, KosTADINIDIs, T., «Dealing with Parallel Universes: Antinomies of Sovereignty and the Protection of National Identity in European Judicial Discourse», Yearbook of European Law, vol. 34, n. ${ }^{\circ}$ 1, 127-169, 2015, p. 129.

64 Pero la verdad es que la lengua no tiene una previsión expresa en el artículo 4.2, de ahí que habitualmente se apoye en el artículo 22 de la Carta o en el 3.3. TUE, por más que sean preceptos con mandatos y destinatarios distintos al 4.2, Arzoz Santisteban, X., «La política lingüística de los Estados miembros y el Derecho de la Unión», Revista Española de Derecho Europeo, n. ${ }^{\circ}$ 52, 2014 (cito por la versión electrónica), en especial epígrafe III. No faltan voces que, tras la clarificación del texto realizada a través del Tratado de Lisboa, y en virtud de la separación de los valores recogidos en el artículo 3, sostienen que debería excluirse cualquier tipo de identidad cultural, Preshova, D., «Battleground or meeting point? Respect for National 
constitucionales_- en el que los dos primeros difícilmente pueden ser criticados como partes de la identidad nacional ${ }^{65}$.

3. La identidad nacional casa mal con el principio de proporcionalidad en la racionalización de las relaciones centro/periferia ${ }^{66}$. No cabe modularla: si un elemento es matizable en conflicto con otros bienes, entonces es irremediable aceptar que carecía de fuerza identitaria ${ }^{67}$. Lo identidad es o no $\mathrm{es}^{68}$. Así las cosas, todo apunta a que la identidad nacional será útil como instrumento material que excluye en términos generales la aplicación del Derecho de la Unión y que cede, también sin ponderación posible, frente a otros bienes. Un buen ejemplo en este sentido es su utilización en relación con la autonomía territorial, que acaba formando, como ya se ha dicho, una presunción en favor del Derecho estatal, que solo se enerva frente a los derechos fundamentales. Es más, me atrevería a sostener que el uso del principio de proporcionalidad acompañando a la identidad nacional acaba siendo en el mejor de los casos un complemento puramente ritual, sin peso, y en el peor fuente de confusiones dogmáticas, tal y como reflejan los asuntos relativos a la religión ${ }^{69}$.

4. Cuando el Tribunal de Justicia reconoce la identidad nacional suele dar una respuesta que ha de ser completada, con un amplio margen de actuación, por parte del juez nacional.

Esta conclusión es cierta siempre que se estime la pretensión estatal; entonces, ha de ser el juez ordinario el que, casi siempre en el marco del principio de proporcionalidad, valore si el caso concreto se subsume bajo la identidad nacional tal y como ha sido delimitada por el Tribunal de Justicia. Muy distinto es el supuesto en el que se rechaza la invocación

Identities in the European Union - Article 4 (2) of the Treaty of the European Union», Croatian Yearbook of European Law and Policy, n. ${ }^{\circ}$ 8, 267-298, 2012, pp. 273 y ss.

65 Es evidente que ha de dominar una interpretación austera de lo que pueda ser la identidad nacional, pero al mismo tiempo parece descartada por el Tribunal un posición que solo incluya bajo al categoría las cuestiones referidas a la forma de Estado o de Gobierno, sobre esta tesis en detalle Dobss, M., op. cit., n. ${ }^{\circ} 59$, pp. 326 y ss.

66 En este sentido, Linden se pregunta si el principio de proporcionalidad puede jugar algún papel fuera de los derechos fundamentales, Linden-ReTEK, P., "Cosmopolitan law and time: Toward a theory of constitutionalism and solidarity in transition», Global Constitutionalism, vol. 4, n. ${ }^{\circ} 2,157-194,2015$, p. 192.

67 Sobre la pérdida del carácter absoluto de la identidad nacional/constitucional cuando compite con el principio de proporcionalidad, Balaguer Callejón, F., «Primato del diritto europeo e identità costituzionale nell'esperienza spagnola», en prensa.

68 Esta sería la tesis del Tribunal Constitucional Federal Alemán, que sostiene un concepto absoluto de la identidad constitucional, cfr. AzPitarte SÁnChez, M., op. cit., n. ${ }^{\circ}$ 15, pp. 950 y ss.

69 Haratsch, op. cit., n. ${ }^{\circ}$ 14, p. 141, propone salir de este dilema distinguiendo entre un contenido nuclear que sería absoluto, y otro contenido que se protegería de «forma relativa». El primero estaría compuesto por las singularidades de un Estado miembro que coincidiesen con los valores de la Unión recogidos en el artículo 2 TUE. Precisamente los valores de ese precepto animarían a rebajar las hipótesis de tensión entre la Unión y los Estados miembros, Bon, P., «La identidad nacional o constitucional, una nueva noción jurídica», Revista Española de Derecho Constitucional, n. ${ }^{\circ}$ 100, 167-188, 2014, p. 187. 
de la identidad nacional. ¿Hay espacio de actuación para el juez estatal? Yo creo que, tal y como señaló el Abogado General P. Cruz Villalón en Gauweiler, solo es viable el sometimiento a la sentencia del Tribunal de Justicia ${ }^{70}$.

TITLE: National Identity and the European Court Legitimacy.

ABSTRACT: This paper tries to know in which way national identity is being used by the European Court of Justice to adjust the center/periphery conflict in the European Union. To this porpoise the main part of the essay arranges and analyzes the jurisprudence, trying to distinguish the general theory elements and the substantive areas where the clause works. Finally, the paper attempts some conclusions.

RESUMEN: El presente trabajo plantea en qué medida la identidad nacional es utilizada para articular por parte del Tribunal de Justicia el conflicto centro/periferia. A estos efectos el núcleo central del trabajo estructura y analiza la jurisprudencia, intentando distinguir los elementos de teoría general y los ámbitos materiales en los que se manifiesta. Finalmente avanza de modo tentativo algunas conclusiones.

KEY WORDS: National Identity, European Court of Justice.

PALABRAs Clave: Identidad nacional, Tribunal de Justicia.

FECHA DE RECEPCIÓN: 10.01.2017

FECHA DE ACEPTACIÓN: 01.02.2017

70 En cambio, von Bogdandy y Schill no excluyen un control posterior del juez estatal, cuya conclusión distinta a la del Tribunal de Justicia habría de verse como el precio a pagar a resultas de la estructura pluralista de la Unión, von Bogdandy, A. y SCHILl, S., op. cit. n. ㅇ 62, p. 1449. 